\title{
Study on the Mechanism of Gas Ignition by Friction Effect of Hard Quartz Sandstone Instability
}

\author{
Li Fuqiang, ${ }^{1,2}$ Qin Guangpeng $\mathbb{D}^{3,4,5}$ Liu Yonggang, ${ }^{1,2}$ Wang Qichen, ${ }^{1,2}$ Wang Ying, ${ }^{1,2}$ \\ and Hou Fengjun ${ }^{1,6}$ \\ ${ }^{1}$ Deep Rock Burst Disaster Assessment Engineering Laboratory of Shandong Province, Jinan, Shandong 250100, China \\ ${ }^{2}$ Third Exploration Team of Shandong Bureau of Coal Geology, Tai'an, Shandong 271000, China \\ ${ }^{3}$ College of Resource, Shandong University of Science and Technology, Tai'an, Shandong 271000, China \\ ${ }^{4}$ National Engineering Laboratory for Coalmine Backfilling Mining, Shandong University of Science and Technology, Tai'an, \\ Shandong 271000, China \\ ${ }^{5}$ Shandong Energy Group Co., Ltd., Jinan, Shandong 250100, China \\ ${ }^{6}$ Shandong Coalfield Geological Planning and Survey Institute, Ji'nan, Shandong 250100, China
}

Correspondence should be addressed to Qin Guangpeng; skd992807@sdust.edu.cn

Received 14 August 2020; Revised 10 November 2020; Accepted 6 December 2020; Published 24 December 2020

Academic Editor: Hualei Zhang

Copyright (c) 2020 Li Fuqiang et al. This is an open access article distributed under the Creative Commons Attribution License, which permits unrestricted use, distribution, and reproduction in any medium, provided the original work is properly cited.

\begin{abstract}
When the upper part of a high gas coal seam has hard and thick sandstone roof, the gas explosion accident in goaf is even caused by roof collapse. Taking the mining of 1007 working face of 10 coal seam under Xia KuoTan Coal Mine as the engineering background, using the method of indoor experiment and theoretical analysis, the possibility of rock friction effect igniting gas is studied. Under the engineering geological conditions, the results show that the heat produced by the friction process of hard sandstone can ignite gas. According to the 3DEC numerical simulation, the instability characteristics of the overburden hard rock are studied. The results show that the size of the slab instability area is not changed when the length of the working face increases. When the thickness of the roof is increased, the area of sliding instability is increased and the degree of sliding instability is more intense. At the boundary of the tunnel, the overlying strata are subjected to the largest shear stress, and it tends to form a friction surface with greater slip instability.
\end{abstract}

\section{Introduction}

A certain concentration of methane and air mixture can form violent oxidation reaction such as explosion or combustion induced by fire source, which will bring great harm [1] to the mine. Due to the wide application of large mining height and fully mechanized caving mining technology, the moving space of roof in the goaf increases, and the probability of friction and impact sparks increase greatly when hard roof collapses. The gas explosion or combustion accident in goaf has occurred from time to time in recent years, which seriously affects [2] coal mine safety production.

By 1887, the Prussian Coal Mine Gas Commission pointed out that the possibility of gas explosion and combustion caused by friction effect when the roof of goaf falls or a large number of rocks in the old roadway are suddenly broken [3], and that conclusion was validated [4] by the U.S. mining agency. A record of the earliest such incidents occurred in November 1896 in the United Kingdom, the [5] gas explosion at the Mainj Peter Mine. Many scholars have also carried out related research by means of experiment and theoretical analysis. Uchida [6], Golinko et al. [7], Qu et al. [8], Yujin et al. [9], and Qu et al. [10] and so on through the test confirmed that the high temperature of the friction effect of the rock such as gravel-bearing coarse sandstone, coarse sandstone, and quartz sandstone and the spark produced has the possibility to detonate the gas. Ward et al. [11] analyzed the potential risk of rock friction igniting gas in Australian coal mines. Kalinchak and Mikhel [12] analyzed the time effect of friction spark ignition gas theoretically. Wang 


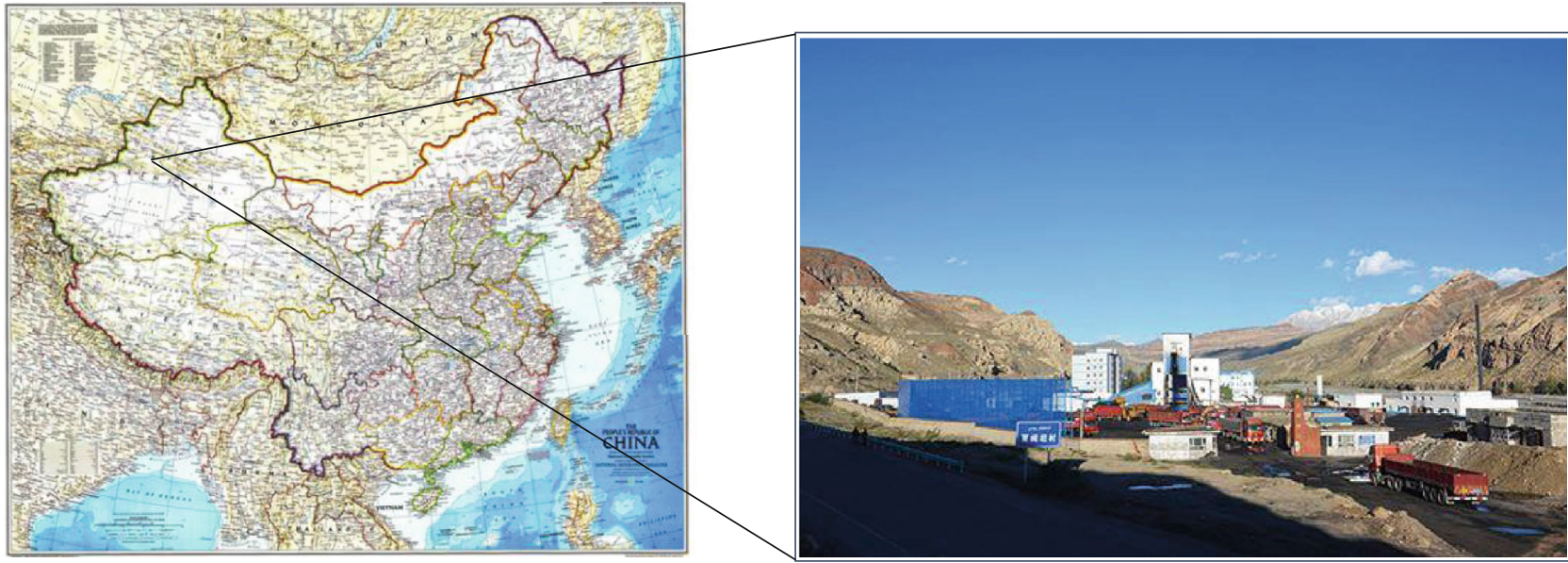

Figure 1: (a) Mine located in XinJiang Province, China. (b) Panorama of the coal mine.

TABLE 1: Roof lithology of 1007 working face.

\begin{tabular}{lcc}
\hline Lithology & Thickness $(\mathrm{m})$ & Features \\
\hline Sandstone and conglomerate & 3.7 & Gravel, quartz content is high, harder \\
Fine sandstone & 2.9 & Fine grain structure, calcium, clay cementing \\
Sandy mudstone & 11.2 & Sand and shale, high sand content partly, sandstone layer interbed \\
Quartz sandstone & 13.9 & High quartz composition, partly quartz stone, very hard \\
Fine sandstone & 6.9 & Glued calcium clay, hard, high quartz composition \\
No. 10 coal seam & 5.5 & Powdery or fragmented, brittle, vertical fissure development \\
\hline
\end{tabular}

et al. [13] studied the possibility of rock collision heating caused by thermal convection to increase the temperature of gas-air mixture and ignite and detonate gas. Bulgakov [14] carried out an experimental study on the gas-air mixture by friction of granite. The conclusion is applied to the analysis of explosion suppression factors of rock collapse and ignition gas in goaf. Qin et al. $[15,16]$ studied the occurrence condition of slide instability and the main ignition source in the case of such gas incidents high-temperature friction surface is more likely to ignite the gas than the spark bundles and hightemperature rock dust due to friction and it is the main ignition source.

The above research confirms the possibility of the friction effect of hard rock to ignite gas from the point of view of theory and test, but the ignition source of igniting gas in rock friction process and the area where the roof rock layer is prone to form friction effect during mining face have not been deeply studied. In the early stage of production, the 1007 working face of Xiakuotan Coal Mine has caused many gas accidents in the goaf during roof collapse. Based on the engineering background of this working face, the main ignition source of gas induced by rock friction effect is determined by test method. Based on 3DEC numerical simulation, the dangerous area of gas in the goaf caused by roof breakage and collapse is analyzed.

\section{Engineering Background}

The Xia KuoTan coal mine is located in the valley area at the south side of the Tianshan Mountain of China (shown in
Figure 1) and has an output of 600 thousand tons coal per year. The mining coal seams No.5, No.7, No.8, No.10, and No.12 layers all are high gassy coal seams. Through laboratory and field tests, for the main mining No.10 coal seam, the relative outflow of gas is $16.3 \mathrm{~m} 3 / \mathrm{t}$, and the absolute outflow of gas is $57 \mathrm{~m}^{3} / \mathrm{min}$. The coal seams are prone to spontaneous combustion, and the spontaneous combustion period is approximately 3 to 6 months.

The 1007 working face lies on the No.10 coal seam without a pseudotop or direct roof. The main roof is composed of fine sandstone and quartz sandstone with an average total thickness of approximately $20.8 \mathrm{~m}$; the composition of which is mainly quartz and feldspar. The rock formation has a good integrity and does not cave easily. The fully mechanized top coal caving method is adopted, the face length is $862 \mathrm{~m}$ and the inclination length is $150 \mathrm{~m}$, the average coal seam thickness is $5.5 \mathrm{~m}$, and the average inclination is $13^{\circ}$. The roof lithology of the working face is shown in Table 1.

When the return lane of the working face was advanced to $55 \mathrm{~m}$ and $173 \mathrm{~m}$, the gas in the gob area was ignited when the roof collapsed, and the gas flame broke into the working space and burned the workers. These incidents occurred as shown in Figure 2.

\section{Flash Temperature Analysis of Friction Effect of Rock Stability}

Due to the action of friction, friction heat is produced in the process of rock block motion, and the mechanical energy of rock block is converted into heat energy. If the contact 


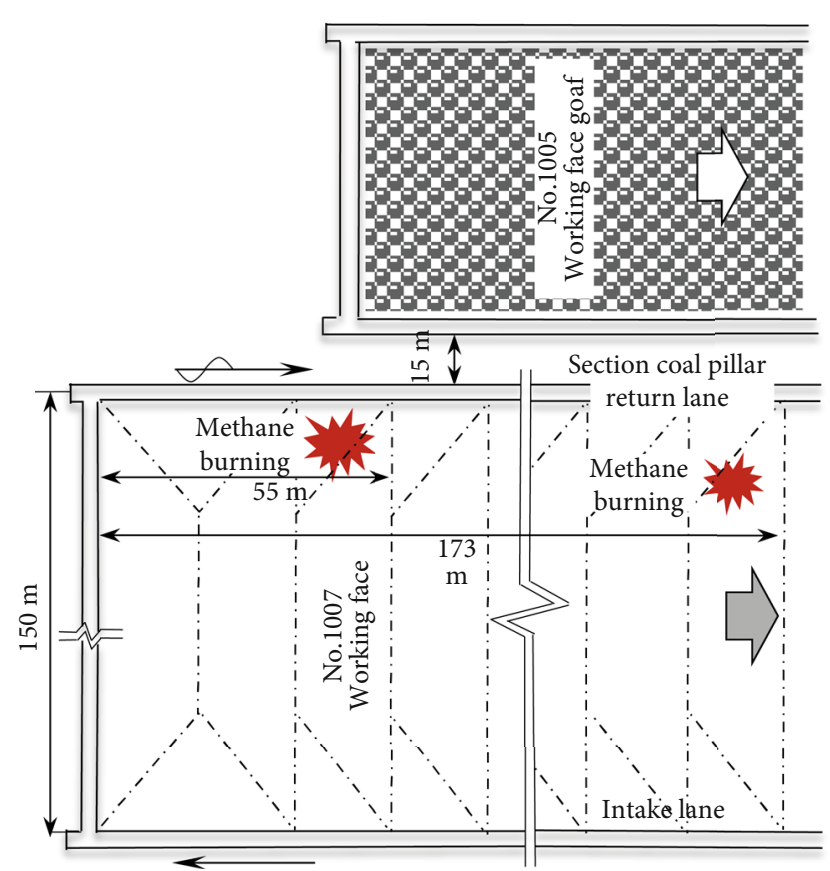

Figure 2: Layout of the working face and incident indication.

surface is uniform, the friction heat will be evenly distributed on the contact surface. However, in practice, the contact surface is always uneven, and there are a large number of microoutburst on the rock surface, which is affected by physical properties such as material and density, and these microoutburst bodies have great contingency. In the process of contact friction, some microconvex bodies will produce hundreds or even thousands of degrees of high temperature on the contact surface because of the large contact area and the very small heat release area, which lasts only a few milliseconds or less. So it is called flash temperature.

The research on friction flash temperature is more studied in the field of metal friction, and the influence of friction flash temperature and flash temperature on rock is less studied. Dangwei and Baisheng [17], based on the heat conduction theory, derived the formula of maximum flash temperature of rock roof collapse and friction surface:

$$
T_{f \max }=K \frac{f \rho_{1} g L_{i}^{2}}{8 h b}\left(\frac{A_{a}}{A_{r}}\right)\left(\left|v_{1}-v_{2}\right| \bar{d}_{\max }\right)^{1 / 2}
$$

In formula (1), $T_{f \max }$ is maximum friction flash temperature; $K$ is correction coefficient, $f$ is dynamic friction coefficient between rock blocks; $\rho 1$ is main roof density, $\mathrm{kg} / \mathrm{m}^{3}$; $L_{i}$ is the span of the three-hinged arch, $\mathrm{m} ; h$ is the main roof thickness, $\mathrm{m} ; \quad b$ is the thermal contact coefficient, $\mathrm{J} /\left(\mathrm{m}^{2} \cdot{ }^{\circ} \mathrm{C} \cdot \mathrm{s}^{1 / 2}\right) ; A_{r}$ and $A_{a}$ is actual and nominal contact area, $\mathrm{m}^{2} ; v_{1}$ and $v_{2}$ is sliding velocity of different period, $\mathrm{m} / \mathrm{s}$; and $\bar{d}_{\max }$ is the average value of the maximum contact diameter of all microconvex bodies.

According to the uniform distribution model of microconvex, the contact parameters $A_{r} / A_{a}$ and $\bar{d}_{\max }$ can be deduced:

$$
\begin{aligned}
\frac{A_{a}}{A_{r}} & =0.3856\left(\frac{E_{m}^{2}}{\sigma_{a}^{2} R^{2} \eta}\right)^{1 / 3}, \\
\bar{d}_{\max } & =1.1284\left(\frac{A_{a}}{A_{r}} \eta\right)^{1 / 2} .
\end{aligned}
$$

In formula (2) and (3), $\eta$ is the density of the microconvex body, $\mathrm{kg} / \mathrm{m}^{3} ; E_{m}$ is the composite modulus of two friction rock blocks, $E_{m}=0.5 E /\left(1-v^{2}\right), \mathrm{MPa}$; $\mathrm{is}$ elastic modulus of rock blocks, $\mathrm{MPa} ; \nu$ is Poisson's ratio of rock blocks; $1 / R$ is composite curvature, because of the convex surfaces contact of microconvex bodies,so $1 / R=4 / d$.

For the 1007 working face of the Xiakuotan Coal Mine, the length of working face is $150 \mathrm{~m}$, the cycle to press step is $25.5 \mathrm{~m}$, the thickness of the first main roof is $6.9 \mathrm{~m}$, the specific heat capacity is $0.5 \times 10^{3} \mathrm{~J} /\left(\mathrm{kg}^{\circ} \mathrm{C}\right)$, the friction coefficient is 0.2 , the roof sliding speed is $6 \mathrm{~m} / \mathrm{s}$, the maximum particle size range of sandstone is $0.5-2.0 \mathrm{~mm}$, and the maximum flash temperature is $1234.57^{\circ} \mathrm{C}$ based on formula (1).

Through analysis and calculation in theory, it can be known that under the engineering and mining conditions of the Xia KuotTan coal mine, when frictional instability occurs in the overlying rock strata of 1007 working face, its highest friction flash temperature reaches the gas explosion temperature, which can ignite and detonate the gas. In the following chapter, indoor tests will be conducted to discuss the explosion or combustion characteristics of gas ignited by the rocks frictional heating effects.

\section{Experimental Analysis of Frictional Effect of Rock and Gas Induced}

Gou [18] analyzed the relationship between the energy conversion and the heating mechanism of rock surface during rock friction and impact theoretically. It is suggested that the heating up of rock collision will cause the heating up of gas-air mixture around it, even combustion and explosion. In the process of rock fall and instability, the main heat convection between friction effect and surrounding gas is thermal friction surface, friction spark beam, and high-temperature rock powder flow. In this section, the test method will be used to analyze the ignition process and main ignition sources of gas.

4.1. Test Equipment and Test Program. The rock samples were analyzed by D/Max 2500PC X-ray diffractometer in the upper end of the working face. The results showed that the main phase of fine grained sandstone roof was quartz, illite, some kaolinite, and a small amount of calcium carbonate magnesium ore, in which the quartz content was 56-68\%. The main phase of quartz sandstone roof is quartz, which contains a small amount of dolomite and trace kaolinite, and the quartz content is between 78 and $91 \%$.

Make rock friction effect gas explosion test box, as shown in Figure 3. The specimen is divided into a rotating specimen and fixed specimen. The rotating specimen is a cylinder of $\varphi 120 \mathrm{~mm} \times 30 \mathrm{~mm}$, which is directly connected with the motor rotating shaft. The fixed specimen is clamped with a special device and contacted with the rotating specimen to form sliding friction between each other. The speed of the 

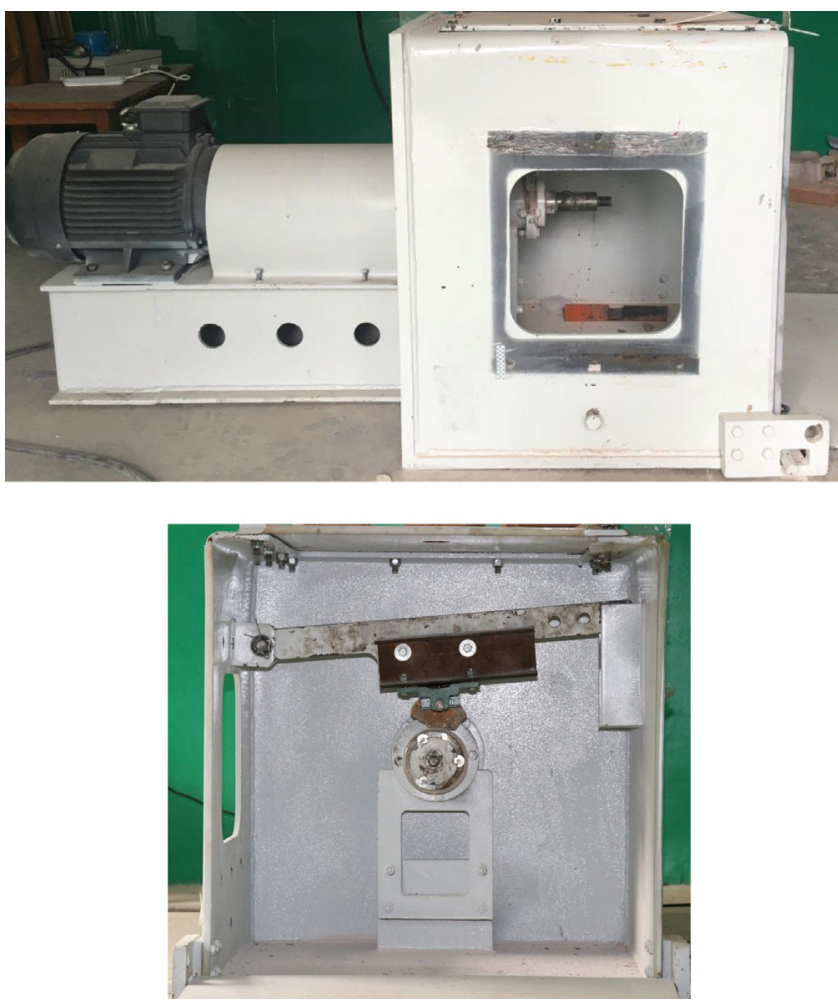

(a) Methane combustion and explosion test box

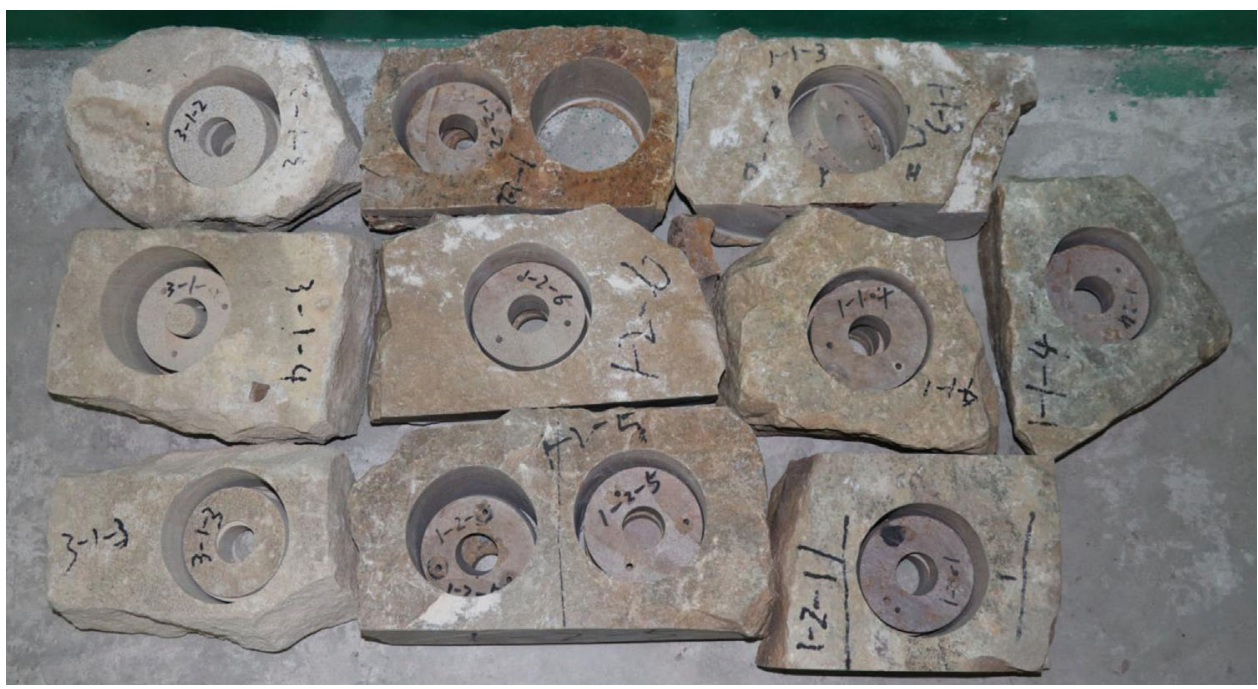

(b) Rock samples and specimen

Figure 3: Test device and specimen.

motor is adjusted by frequency converter to change the friction speed between the two specimens. The gas is injected into the lower part of the experimental box, and the gas sensor is set up in the upper part to detect the gas concentration in the experimental box. The whole process is recorded by high-speed camera equipment, and the test process is analyzed by frame screenshot.

4.2. Characteristics of Frictional Heat Effect Induced Gas Ignition by Hard Sandstone. During the process of sliding and instability after rock failure, severe friction will occur between broken rock blocks, the friction surface will rise to a very high temperature in a short period, and the sparks and hot rock particles will be thrown away from the friction surface. Spark bundles and high-temperature rock powder flow may become potential ignition sources. The gas concentration in the test is between $6 \%$ and $12.8 \%$. Three groups of the same lithology specimens were selected for 24 tests, and the single test time was controlled within 20 s. The test results are shown in Table 2.

The results show that for hard sandstone with high quartz content, when the gas is in the range of combustion 
TABLE 2: Gas ignition results of hard sandstone friction test.

\begin{tabular}{|c|c|c|c|c|c|c|c|c|c|}
\hline Number & $\begin{array}{l}\text { Specimen } \\
\text { number }\end{array}$ & $\begin{array}{c}\text { Friction } \\
\text { velocity }(\mathrm{m} / \mathrm{s})\end{array}$ & $\begin{array}{c}\text { Gas } \\
\text { concentration } \\
(\%)\end{array}$ & Test results & Number & $\begin{array}{l}\text { Specimen } \\
\text { number }\end{array}$ & $\begin{array}{c}\text { Friction } \\
\text { velocity }(\mathrm{m} / \mathrm{s})\end{array}$ & $\begin{array}{c}\text { Gas } \\
\text { concentration } \\
(\%)\end{array}$ & $\begin{array}{l}\text { Test } \\
\text { results }\end{array}$ \\
\hline 1 & $1-1$ & 1.99 & 11.9 & Unexploded & 13 & $1-1$ & 6 & 10.3 & Explosion \\
\hline 2 & $1-2$ & 2 & 10.2 & Unexploded & 14 & $1-1$ & 6 & 8.6 & Explosion \\
\hline 3 & $1-1$ & 4 & 10 & Explosion & 15 & $1-2$ & 6 & 7.7 & Explosion \\
\hline 4 & $1-1$ & 4 & 6.8 & Unexploded & 16 & $1-2$ & 6 & 9.1 & Explosion \\
\hline 5 & $1-2$ & 4 & 10.1 & Explosion & 17 & $1-2$ & 6 & 10.5 & Explosion \\
\hline 6 & $1-2$ & 4 & 6.6 & Unexploded & 18 & $1-2$ & 6 & 12.8 & Explosion \\
\hline 7 & $1-3$ & 4.02 & 10.5 & Explosion & 19 & $1-3$ & 7.99 & 10 & Explosion \\
\hline 8 & $1-3$ & 5.94 & 6.5 & Explosion & 20 & $1-1$ & 8 & 12.4 & Explosion \\
\hline 9 & $1-3$ & 5.98 & 9.7 & Explosion & 21 & $1-2$ & 8 & 10 & Explosion \\
\hline 10 & $1-1$ & 5.99 & 10.5 & Explosion & 22 & $1-3$ & 9.96 & 9.8 & Explosion \\
\hline 11 & $1-1$ & 6 & 6 & Unexploded & 23 & $1-1$ & 10 & 10.9 & Explosion \\
\hline 12 & $1-1$ & 6 & 12 & Explosion & 24 & $1-2$ & 10 & 9.9 & Explosion \\
\hline
\end{tabular}

or explosion concentration, the friction velocity between the specimens determines the possibility of gas ignition. The higher the relative friction velocity, the greater the release energy density, the more easily the gas is ignited. Taking the test process of No.9 specimen as an example, the initial shape of friction spark becomes the origin of time, and the process of spark formation until gas is detonated is analyzed, as shown in Figure 4.

During the test, friction sparks first appear in the form of point sparks, with short duration and low spark energy. The appear time of the point sparks is $1.217 \mathrm{~s}$ shows in Figure 4(b). After two frames (1.250), spark duration is only $0.033 \mathrm{~s}$ less than the time requirement of ignition gas. For a longer period of time $(0-2.817 \mathrm{~s})$, The friction heat of rock mass accumulates near the friction surface. Point sparks gradually form spark beams. As in $2.817 \mathrm{~s}$, compared to point sparks, the spark beam is brighter and contains more energy and lasts longer, but it is still not enough to ignite gas. It shows that the thermal convection between the energy contained in the spark beam and the gas-air mixture does not heat the gas to the ignition point, $4.650 \mathrm{~s}$. A more intense beam of sparks is ejected from the friction surface with a small amount of ignited gas. Gas is then continuously ignited near the friction surface (4.667 s). And spread it all around, until the explosion of gas in the whole experimental box ( $4.667 \mathrm{~s}-4.867 \mathrm{~s}$ ).

It can be seen that when the gas concentration is suitable, the rock friction effect can ignite and detonate the gas. However, the maximum temperature of rock friction cannot be easily recorded by test, and the maximum friction flash temperature of friction surface is calculated by theoretical analysis.

\section{Numerical Simulation Analysis on the Position of Sliding Unstable Friction Surface in Longwall Face}

\subsection{DEC Numerical Model}

5.1.1. Establishment of Numerical Model. According to the \#10 coal surface mining conditions and geological conditions to establish numerical model, as shown in Figure 5. The width of the model is $300 \mathrm{~m}$, the length is $400 \mathrm{~m}$, the height is $160 \mathrm{~m}$, and the 42223 blocks are divided.

The top of the model is free surface, the uniform load of $10 \mathrm{MPa}$ is applied, the lateral pressure coefficient is 0.3 , and the model limits the displacement of the four weeks and the bottom. According to engineering geology report, the physical and mechanical properties of the overlying rock in the coal seam were tested through laboratory tests, and the physical and mechanical parameters of the relevant rock layers were obtained. The physical and mechanical parameters of the main strata of the model are shown in Table 3.

5.1.2. Simulation Program and Arrangement of the Monitoring Points. The influence of the length of the working face and the thickness of the basic roof rock on the formation of the friction surface of the rock fall. Respectively, the design for the length of the face $L=200 \mathrm{~m}, 250 \mathrm{~m}$, the lower base of the basic thickness of $H=1.5 \mathrm{M}, 2.5 \mathrm{M}$ ( $\mathrm{M}$ for the mining height) different conditions for comparative analysis, along the return airway in the face of mining $70 \sim 110 \mathrm{~m}$ area to layout measurement points. In the measuring area, there are five measuring lines arranged at $70 \mathrm{~m}, 80 \mathrm{~m}, 90 \mathrm{~m}, 100 \mathrm{~m}$, and $110 \mathrm{~m}$, and each measuring line is arranged along the middle of the roadway to the middle of the working face. A total of 25 measuring points were arranged in the survey area, as shown in Figure 6.

5.2. Effect of Length of Working Face on the Position of Friction Surface. When the length of the working face is gradually increased, the position of the fault line along the working surface tends to change, so the position of the unstable friction surface may change. In this paper, the shear stress variation of each measuring point in the mining face is studied, and the possibility of the falling of the block is determined. The situation and timing of the falling point of the measuring point are analyzed. The influence of the length of the working face on the instability zone of the mined out area is determined. Regardless of the simulated initial 


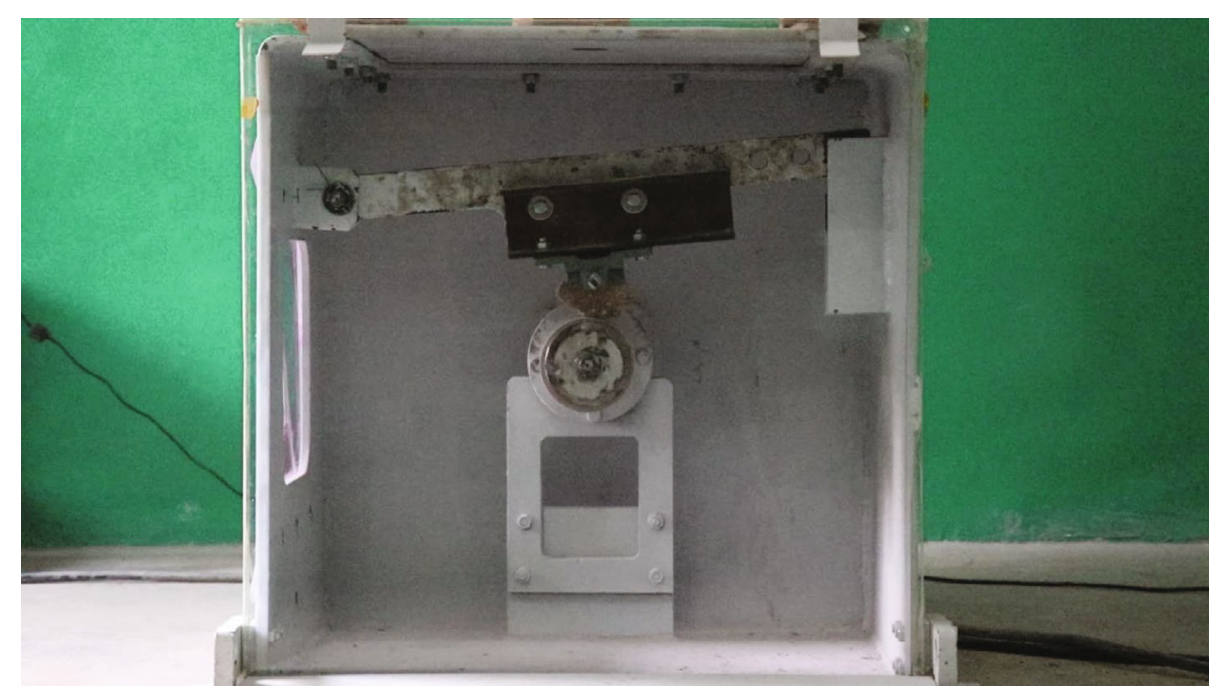

(a) $0 \mathrm{~s}$

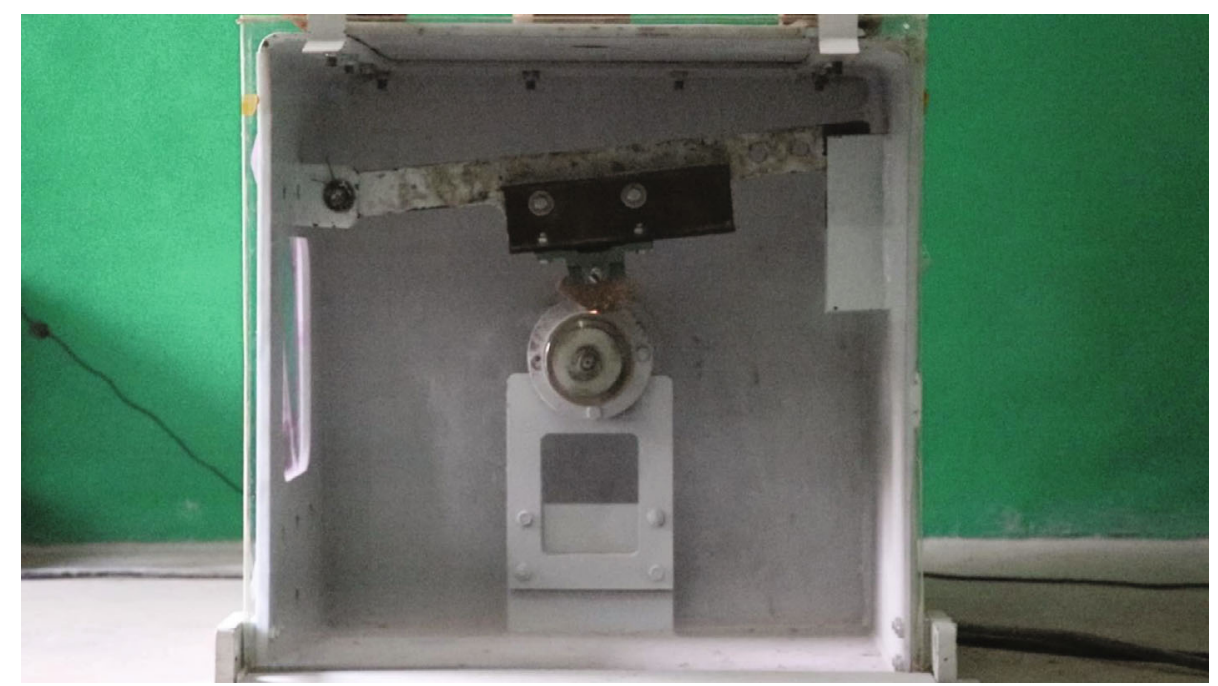

(b) $1.217 \mathrm{~s}$

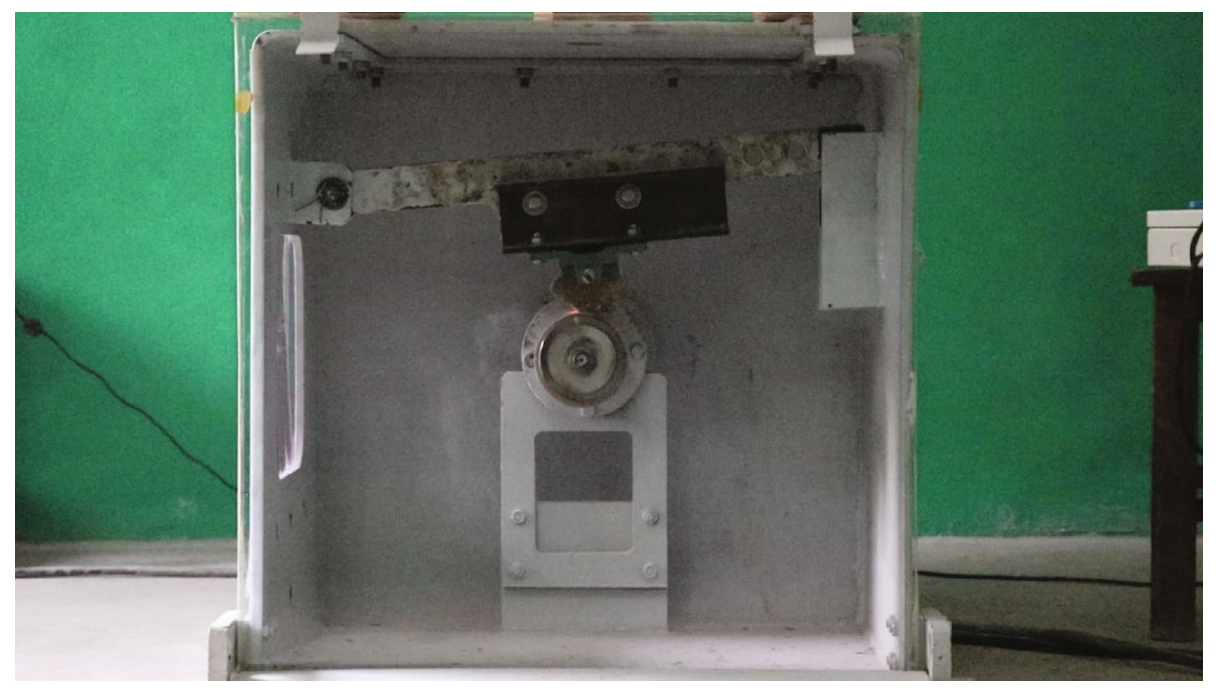

(c) $2.817 \mathrm{~s}$

Figure 4: Continued. 


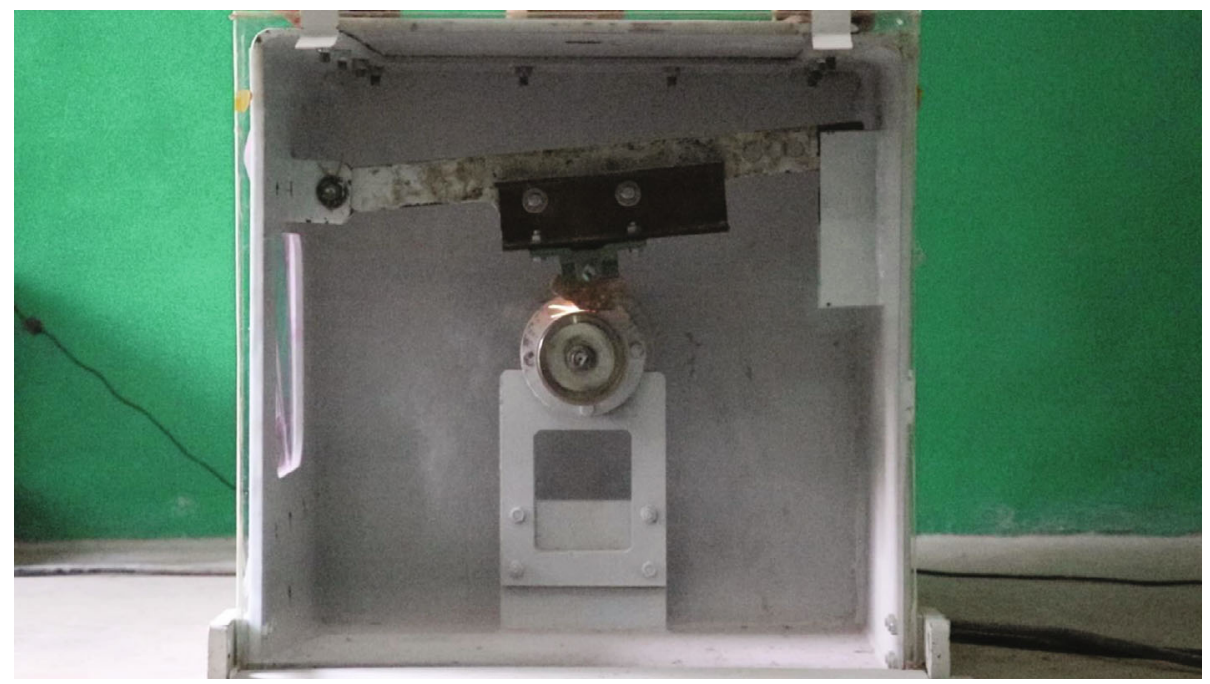

(d) $4.650 \mathrm{~s}$

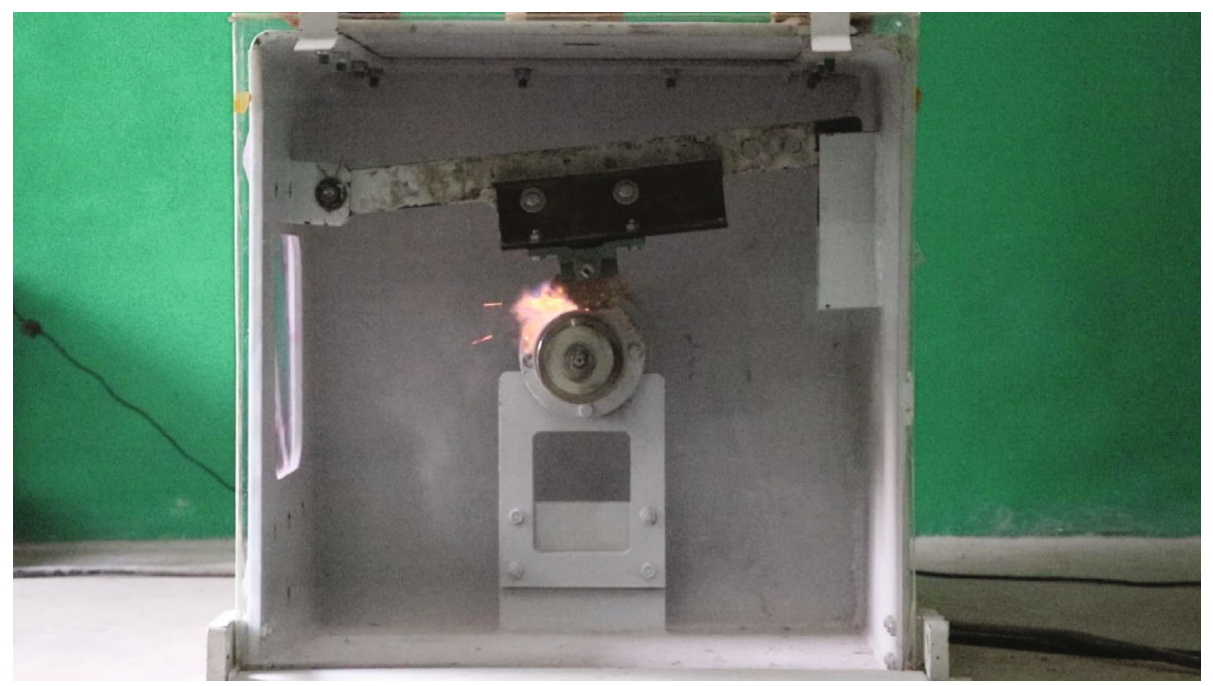

(e) $4.667 \mathrm{~s}$

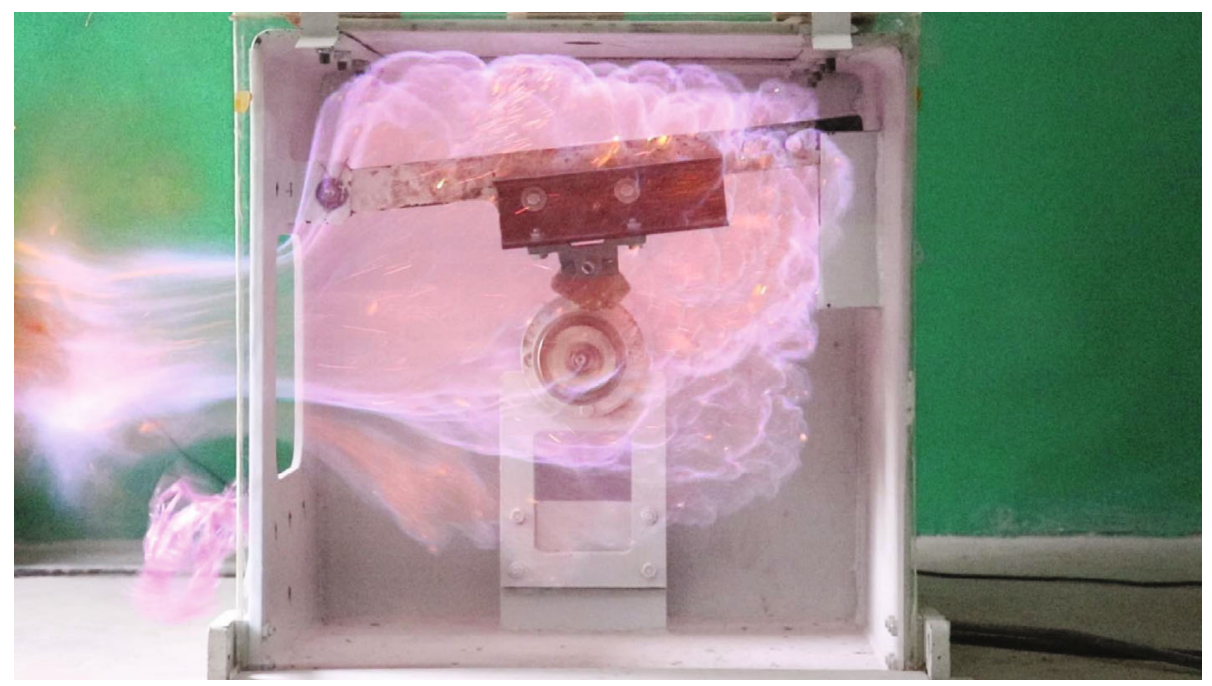

(f) $4.867 \mathrm{~s}$

Figure 4: Process of hard sandstone friction spark inoculation and gas ignition. 


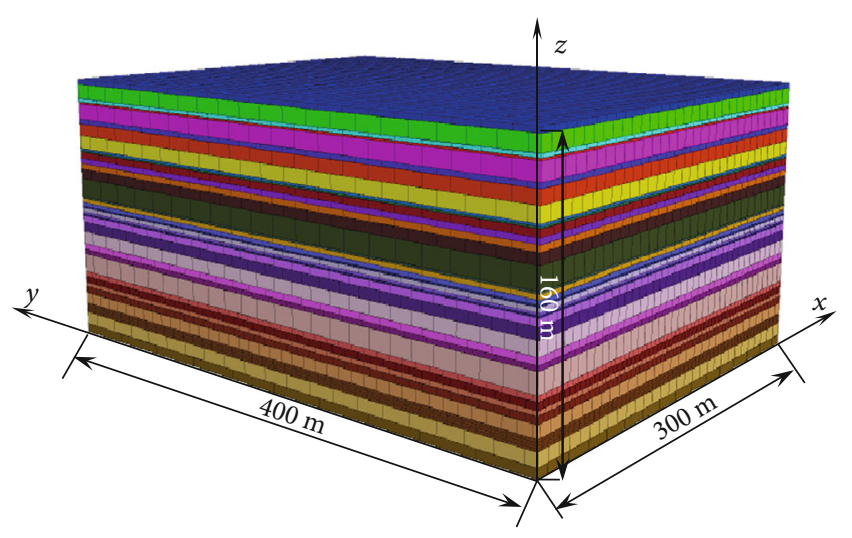

Figure 5: \#10 coal seam numerical model.

equilibrium stress values, the analytical data starts from the face excavation (corresponding to the starting cycle number of steps of 8800). Subject to the impact of advanced support pressure, the curve in the 13,500 steps around the peak stress. After the face passes, the stress drops and the stress remain stable over a range. When the number of cycles is in the range of 20000 25000, the stress curve fluctuates again. This area is the main research scope, which is called stress fluctuation area in this paper.

5.2.1. $L=200 m, H=1.5 M$, Friction Surface Position Analysis. When the basic roof thickness is 1.5 times the thickness of the mining work, the maximum shear stress of the surface length $200 \mathrm{~m}$, as shown in Figure 7.

At the $70 \mathrm{~m}$ line, as shown in Figure $7(\mathrm{a})$, point 1 is affected by the support of the coal wall, and the shear stress value is always at a high level, in the boundary position prone to fall instability. Measuring point 2 shear stress changes more gentle. The maximum shear stress at point 3 and point 4 increases abruptly and remains relatively stable in stress fluctuation zone. Due to the sudden increase in shear stress exceeding the friction between the rock, this position may occur with falling rock block instability. The maximum shear stress of the measuring point 5 in the stress fluctuation area first after the sharp rise to maintain a period of time stability, and then quickly decline, shear stress followed by multiple fluctuations. It is shows that at the point of measurement 5, the rock mass appears to stage sliding instability. In the process of sliding instability, there has been a temporary balance, the temporary equilibrium state is broken, and the rock blocks continue to slip until the final settlement to the equilibrium position.

At the $80 \mathrm{~m}$ line, as shown in Figure 7(b), point 1 shear stress rise steadily, at the maximum stress, with a greater possibility of falling instability. The shear forces at points 2 and 3 are relatively stable. The shear stress of the measuring points 4 and 5 showed a double peak fluctuation in the stress fluctuation area.

At the $90 \mathrm{~m}$ line, as shown in Figure 7(c), point 1 shear stress rises steadily, at the maximum stress at each point. Points 2 and 3 shear stress is relatively stable, and fall instability may be smaller. Point 4 shear stress fluctuates in the fluctuation zone, but the peak value is small. In this position, the rock mass may occur in the stage sliding instability, but the slip intensity is small. Point 5 shear stress generated jumping, a short period of time the rapid increase in stress, and then showed a wave-like stability, which indicates that the rock mass of the point is slipping and unstable. It is shown that the point 5 rock burst instability after the formation of a stage sliding instability.

At the $100 \mathrm{~m}$ line, as shown in Figure 7(d), the shear point of point 1 rises steadily to the maximum point, with the largest slip trend. The shear forces at points 2 and 3 are relatively stable. The shear stress of the point 4 is increased to the maximum value except the boundary point, and it fluctuates slightly in the stress fluctuation area. The slip at this position may be the largest outside the boundary point. The shear stress of the point 5 exhibits a peak fluctuation in the stress fluctuation area and tends to be balanced after the shock. It is shown that the rock mass in point 5 occurred with sliding instability, but the sliding intensity is relatively weak.

At the $110 \mathrm{~m}$ line, as shown in Figure 7(e), point 1 shear force remained stable after rising steadily. The shear stress of points 2,3, and 5 is relatively stable in the stress fluctuation zone, and the possibility of falling instability is low. The shear stress of measuring point 4 gradually increases to the high stress level in the stress fluctuation zone, and the possibility of the shear stress gradually increases with the increase of the shear stress.

From the above analysis, we can see that the area is easy to produce sliding instability and form a friction surface, as shown in Figure 8.

5.2.2. $L=250 \mathrm{~m}, H=1.5 \mathrm{M}$, Friction Surface Position Analysis. When the basic roof thickness is 1.5 times the thickness of the mining work, the maximum shear stress of the surface length is $250 \mathrm{~m}$, as shown in Figure 9.

At the $70 \mathrm{~m}$ line, as shown in Figure 9(a), point 1 is affected by the support of the coal wall, the shear stress value is always at a high level, in the boundary position prone to fall instability. Points 2 and 3 shear stress is relatively stable, resulting in falling instability being lower. Point 4 shear stress tends to be stable after sudden increase in stress fluctuation area and rapid decline. It is shown that point 4 rock mass has fallen to form a friction surface. The shear stress of point 5 produces a bimodal fluctuation in the stress fluctuation area, indicating that the point 5 rock mass produces a stage sliding instability.

At the $80 \mathrm{~m}$ line, as shown in Figure 9(b), point 1 shear stress rises steadily, at the maximum stress, with a greater possibility of falling instability. The shear stress changes in points 2 and 3 are relatively stable. The shear stress of the point 4 showed a bimodal fluctuation, and the shear stress of the point 5 showed a bimodal fluctuation after the rise of the stress low, indicating that the rock mass occurred to stage sliding instability at the points 4 and 5 , and the friction surface was formed.

At the $90 \mathrm{~m}$ line, as shown in Figure 9(c), the shear stress of the point 1 decreases steadily and then decreases, indicating that the boundary rock mass produces a certain stage sliding instability. The shear stress of the rock mass at the measured points 2 and 3 is relatively stable. The shear stress 
TABLE 3: Lithology parameters.

\begin{tabular}{|c|c|c|c|c|c|c|}
\hline Lithology & $\begin{array}{l}\text { Bulk modulus } \\
\quad(\mathrm{GPa})\end{array}$ & $\begin{array}{l}\text { Shear modulus } \\
\quad(\mathrm{GPa})\end{array}$ & $\begin{array}{c}\text { Cohension } \\
(\mathrm{MPa})\end{array}$ & $\begin{array}{c}\text { Internal friction } \\
\text { angle }\left(^{\circ}\right)\end{array}$ & $\begin{array}{c}\text { Tensile strength } \\
(\mathrm{MPa})\end{array}$ & Density $\left(\mathrm{kg} \cdot \mathrm{m}^{-3}\right)$ \\
\hline Coal & 0.97 & 0.90 & 1.10 & 20 & 1.34 & 1300 \\
\hline Sandy mudstone & 2.20 & 1.21 & 2.10 & 25 & 1.83 & 2340 \\
\hline Siltstone & 4.40 & 2.90 & 2.50 & 28 & 2.18 & 2696 \\
\hline Fine sandstone & 5.87 & 4.38 & 3.26 & 30 & 3.19 & 2700 \\
\hline Quartz sandstone & 8.06 & 7.89 & 5.80 & 32 & 4.54 & 3300 \\
\hline
\end{tabular}

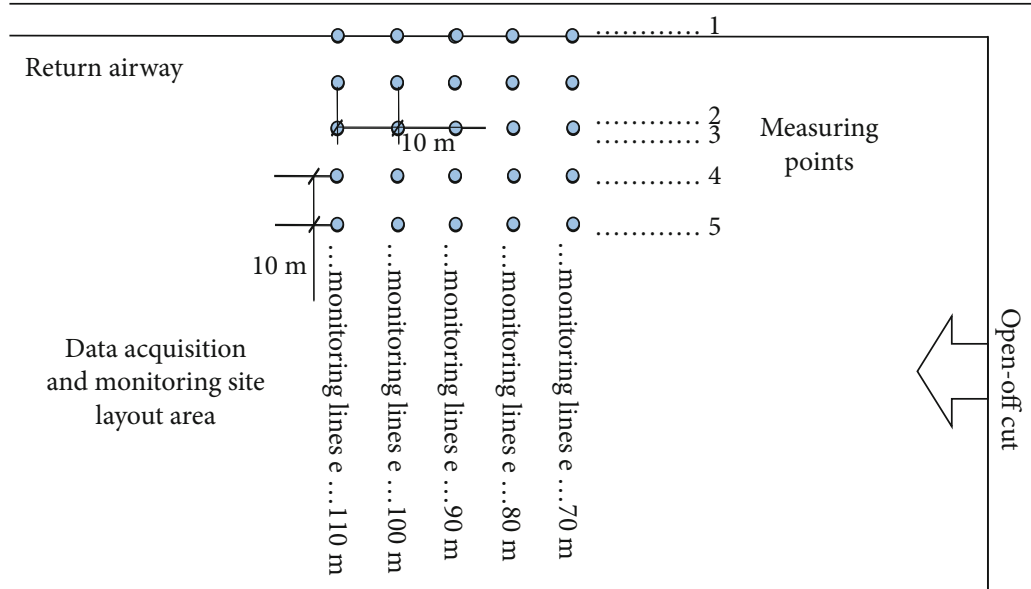

Intake airway

FIGURE 6: Schematic diagram of measuring points.

of the point 4 rock mass rises and falls within the stress fluctuation zone for a period of time and then falls to a relatively low stress position, and the amplitude of the curve is not significant. There was a certain distance slip in the rock at point 4 , but the slip intensity was not significant. The shear stress of point 5 shows a bimodal fluctuation in the stress fluctuation area, indicating that the rock has a stage sliding instability.

At the $100 \mathrm{~m}$ line, as shown in Figure 9(d), the shear stress of point 1 rock mass rises to about $7 \mathrm{MPa}$ and then suddenly decreases, indicating that the boundary rock mass has fallen. The shear stress of the points 2 and 3 rock mass is relatively stable, and the possibility of falling instability is low. The shear stress of measuring point 4 is rapidly increasing in the stress fluctuation area and falls after reaching the peak, indicating that the point 4 position rock mass was produced by falling instability to form the friction surface. The shear stress of the measuring point 5 shows a tendency to fluctuate in the stress fluctuation area, and it is stable after the stress is high. It can be seen that there is a possibility that the rock mass increases with the increase of shear stress at point 5.

At the $110 \mathrm{~m}$ line, as shown in Figure 9(e), the shear stress of point 1 rises steadily, the shear stress of the boundary rock mass increases gradually, and the sliding tendency increases gradually. The shear stress changes in points 2,3 , and 4 are smooth and there is no large fluctuation, indicating that the rock slips are less likely to slip at these points. The maximum shear stress of measuring point 5 in the stress fluctuation zone is fluctuating after the weak fluctuation, and it is stable after the weak descent, indicating that the rock mass is unstable and the friction surface is generated at this point.

From the above analysis, we can see that the area is easy to produce sliding instability and form a friction surface, as shown in Figure 10.

In summary, through comparative analysis with the maximum shear stress curve from the length of different working surface and the area where easy to be sliding instability, we can see that the shear stress in the roof rock of the roadway boundary is the maximum of each point. So, the location of the rock is more easily broken and the occurrence of falling instability to form a friction surface. With the increase of the length of the working face, the change of the area falling within the working area is not very large.

5.3. Influence of Roof Thickness of Working Face on the Position of Friction Surface. When the thickness of the roof increases, the energy required for the rupture of the roof increases, which will have a certain influence on the location of the fracture and the location of the friction surface. When the basic roof thickness is 2.5 times the thickness of the mining work, the maximum shear stress of the surface length $200 \mathrm{~m}$, as shown in Figure 11. 


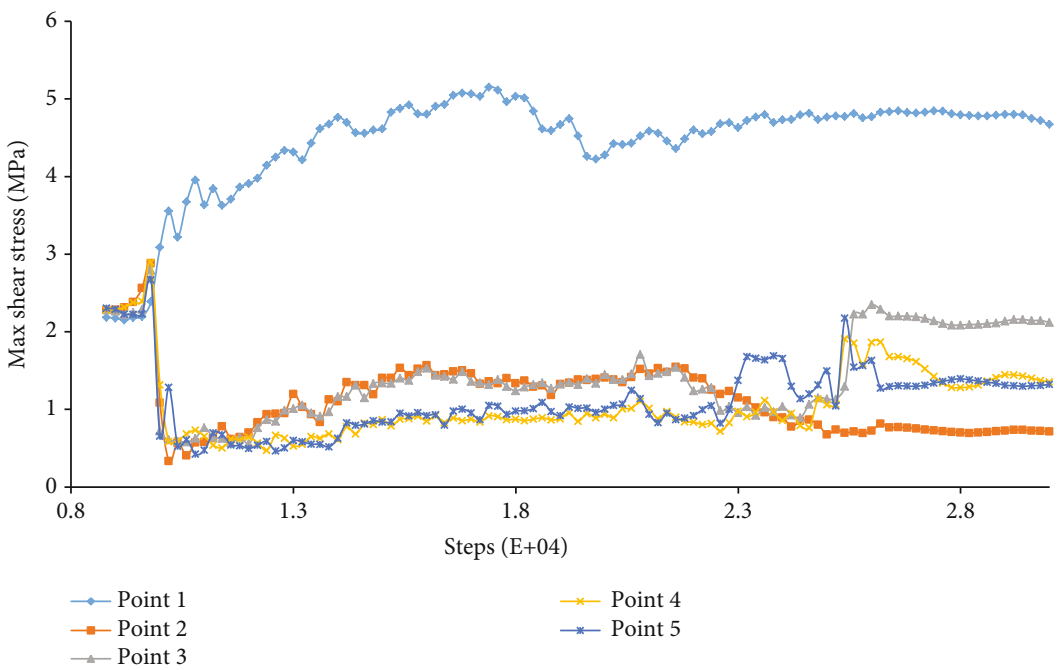

(a) $70 \mathrm{~m}$ line

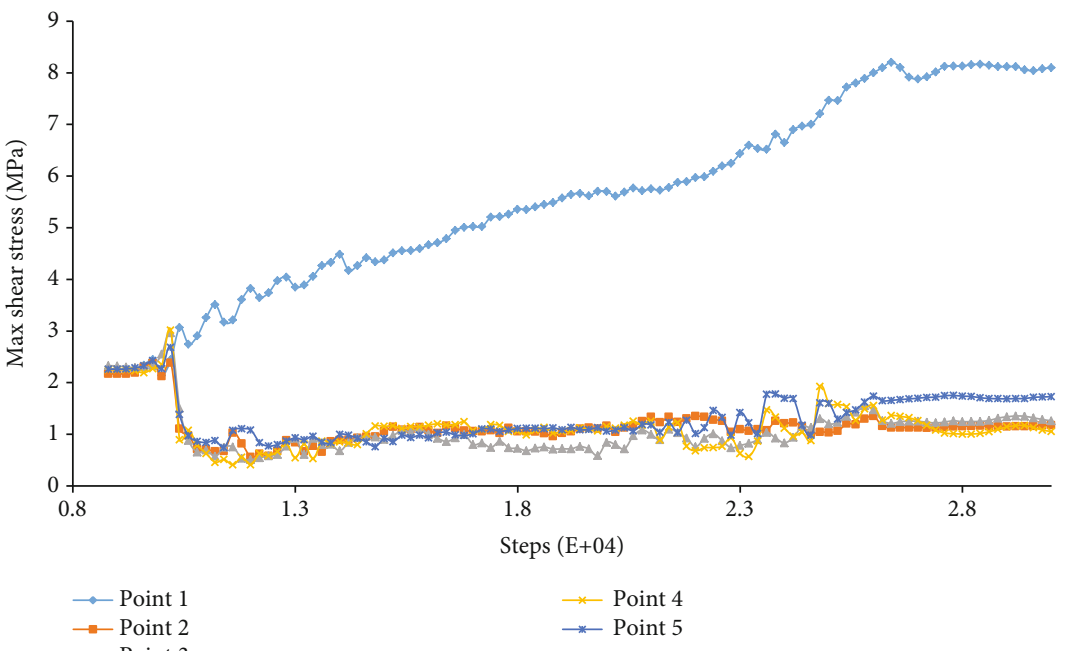

(b) $80 \mathrm{~m}$ line

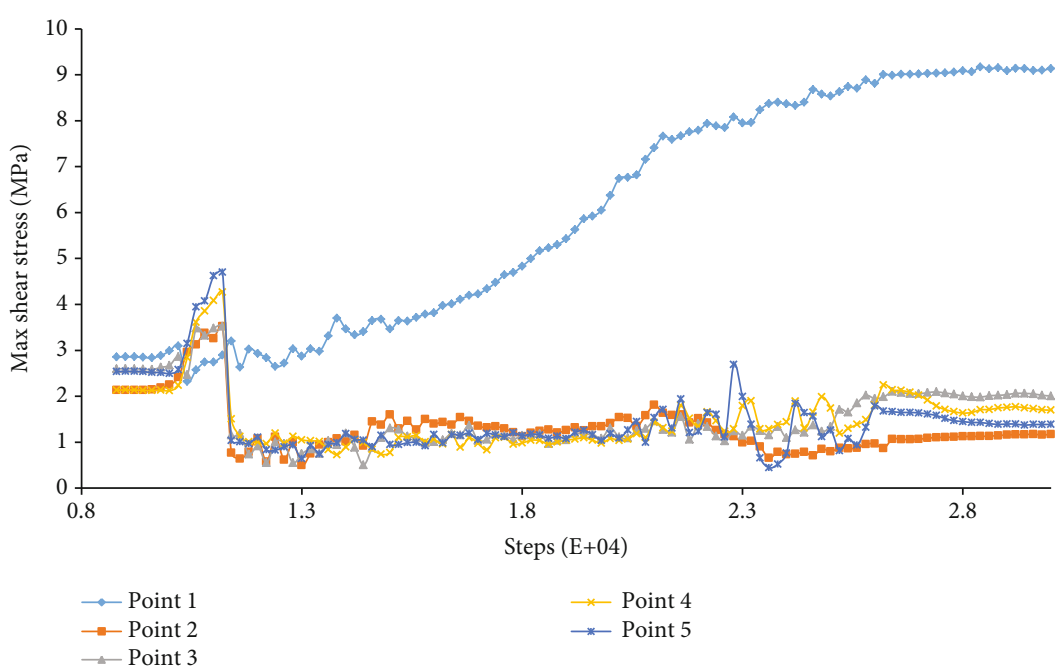

(c) $90 \mathrm{~m}$ line

FIgURE 7: Continued. 


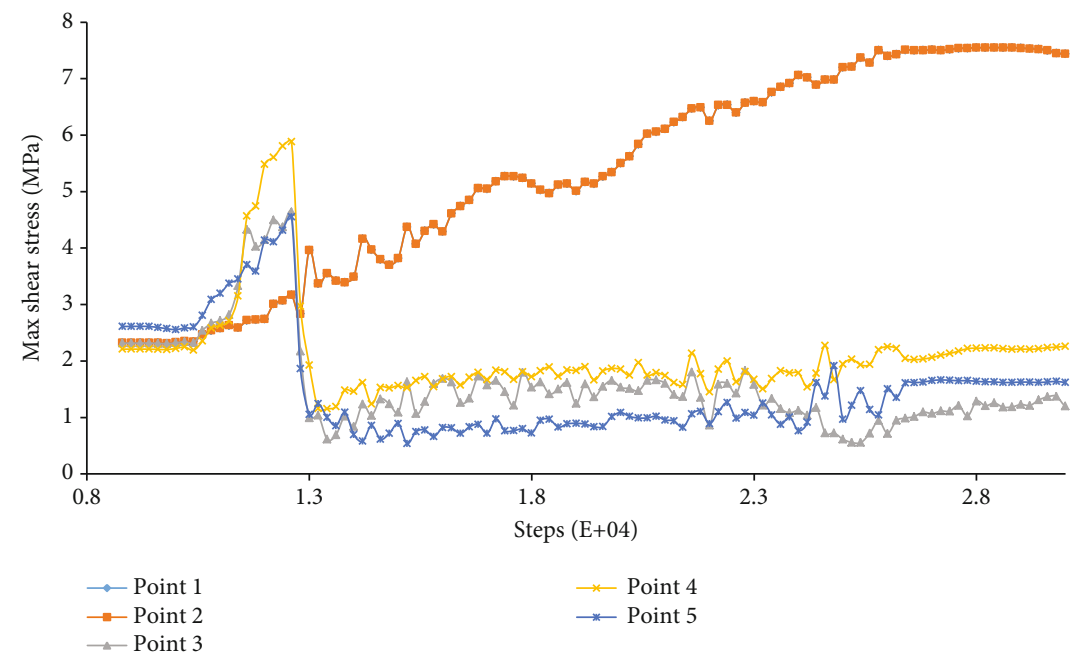

(d) $100 \mathrm{~m}$ line

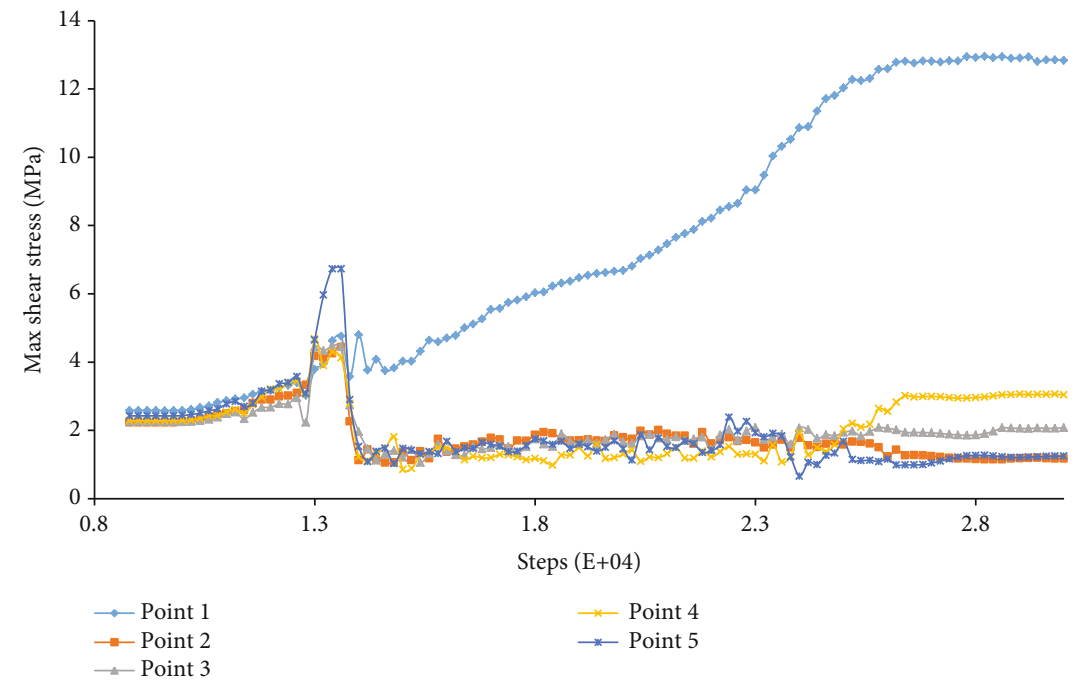

(e) $110 \mathrm{~m}$ line

Figure 7: $L=200 \mathrm{~m}, H=1.5 \mathrm{M}$ shear stress trends.

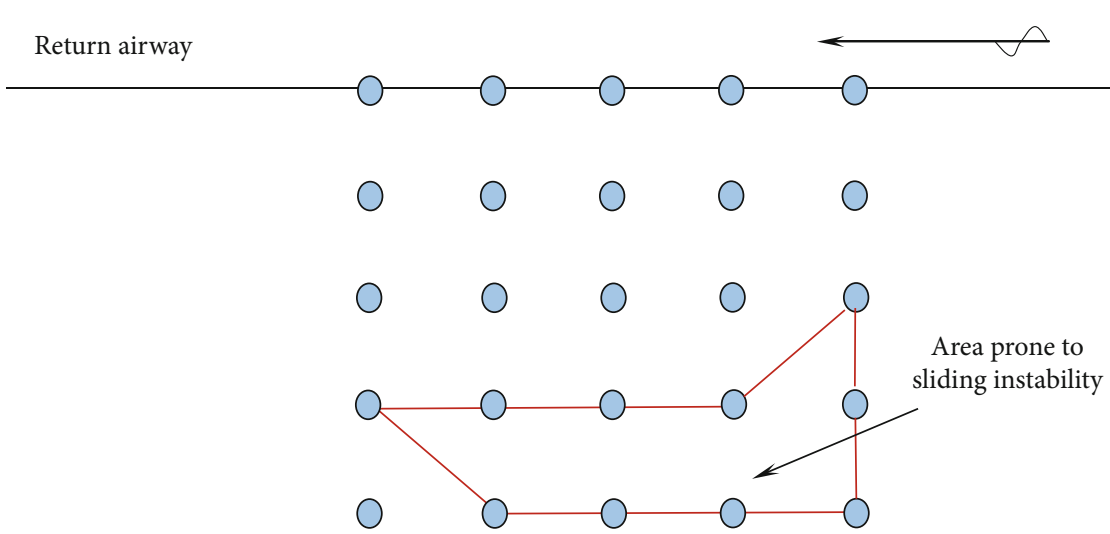

Figure $8: L=200 \mathrm{~m}, H=1.5 \mathrm{M}$ of the face prone to instability area.

At the $70 \mathrm{~m}$ line, as shown in Figure 11(a), point 1 shear stress rises steadily, and the steady increase in stress occurs after the decrease of the stress in the stress fluctuation area.
It is shown that with the rapid increase of the shear stress in the stress, the rock mass in test point 1 will have a greater tendency and more possibility to producing the friction 


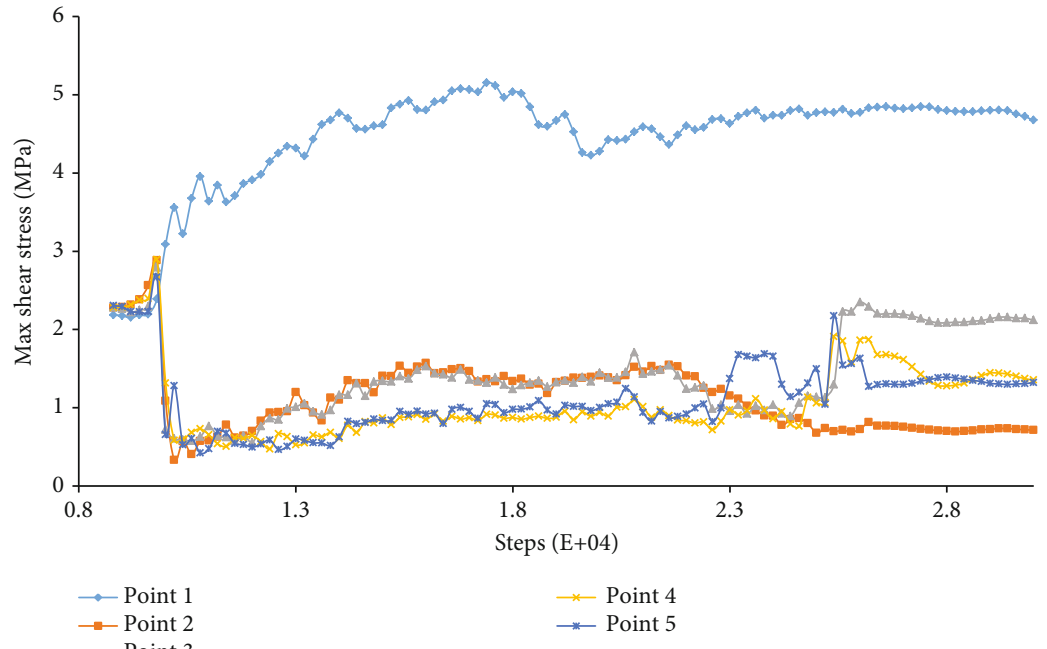

(a) $70 \mathrm{~m}$ line

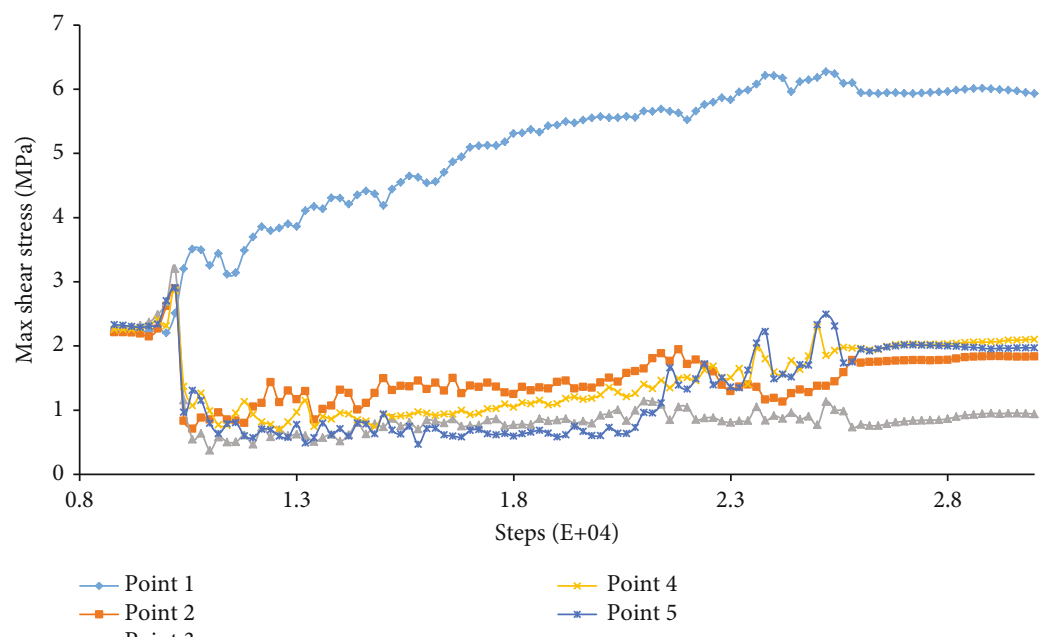

(b) $80 \mathrm{~m}$ line

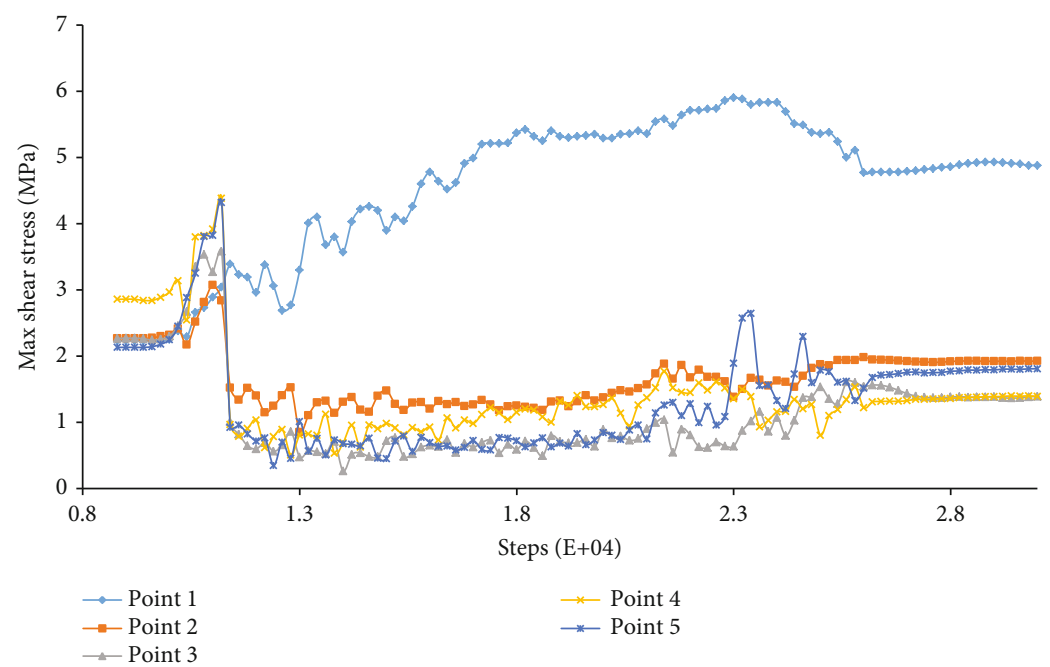

(c) $90 \mathrm{~m}$ line

Figure 9: Continued. 


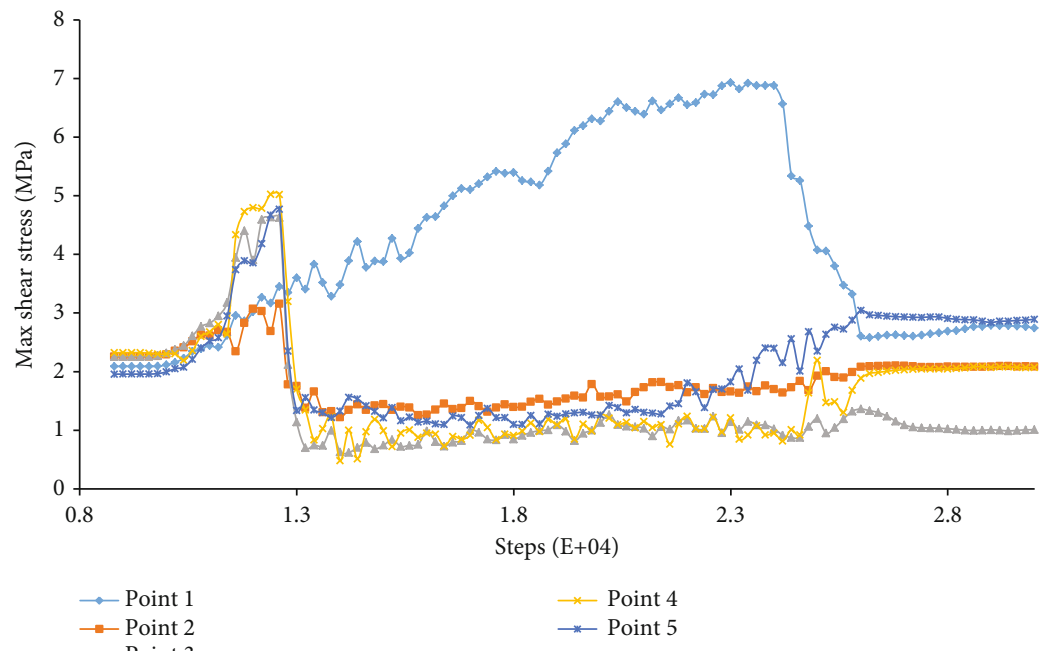

(d) $100 \mathrm{~m}$ line

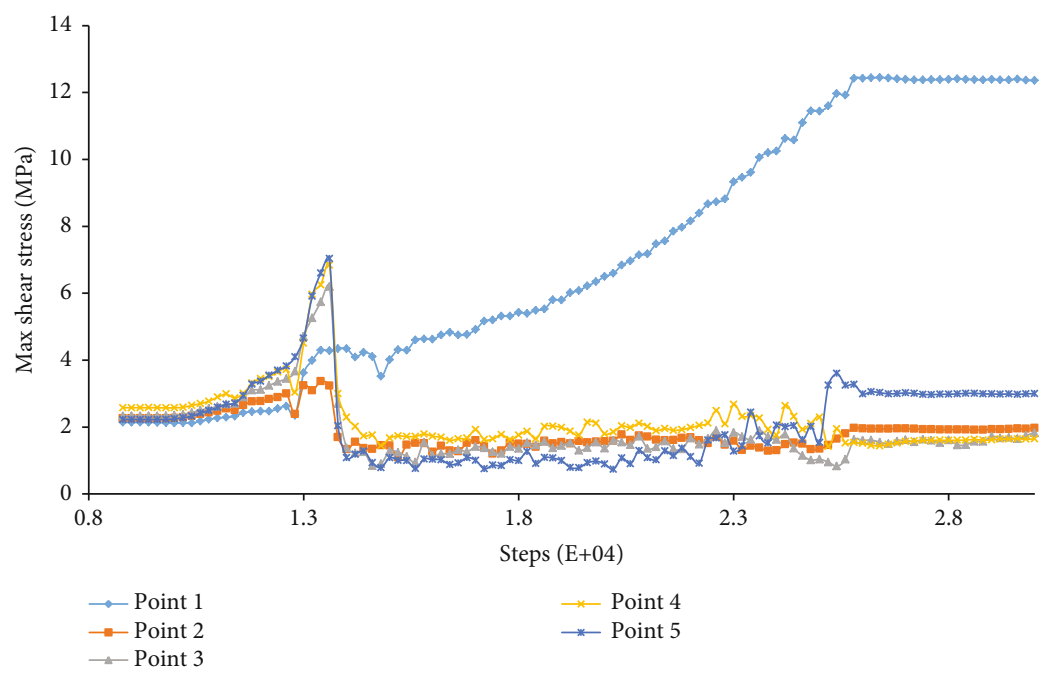

(e) $110 \mathrm{~m}$ line

Figure 9: $L=250 \mathrm{~m}, H=1.5 \mathrm{M}$ shear stress trends.

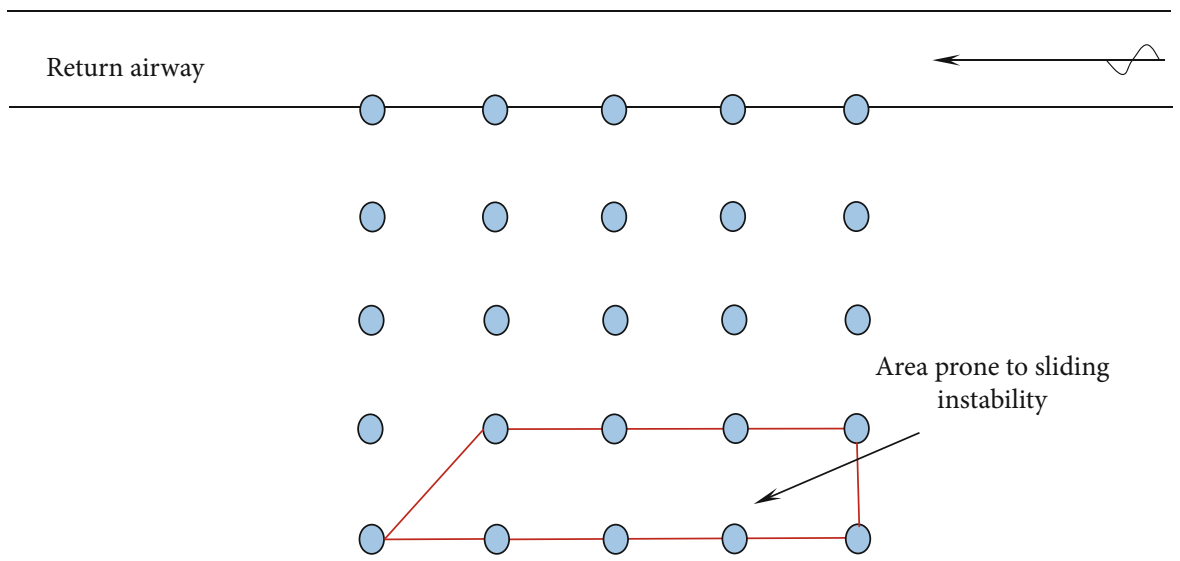

Figure 10: $L=250 \mathrm{~m}, H=1.5 \mathrm{M}$ of the face prone to instability area.

surface. Points 2 and 3 shear stress are relatively stable and steadily rise after the stay in a stable state. Point 4 shear stress increases in the stress fluctuation area and falls to the lower stress level and remain stable after three peaks occur. It is shown that the rock mass in test point 4 is unstable, but the slip intensity is not very intense. Point 5 shear stress is the 


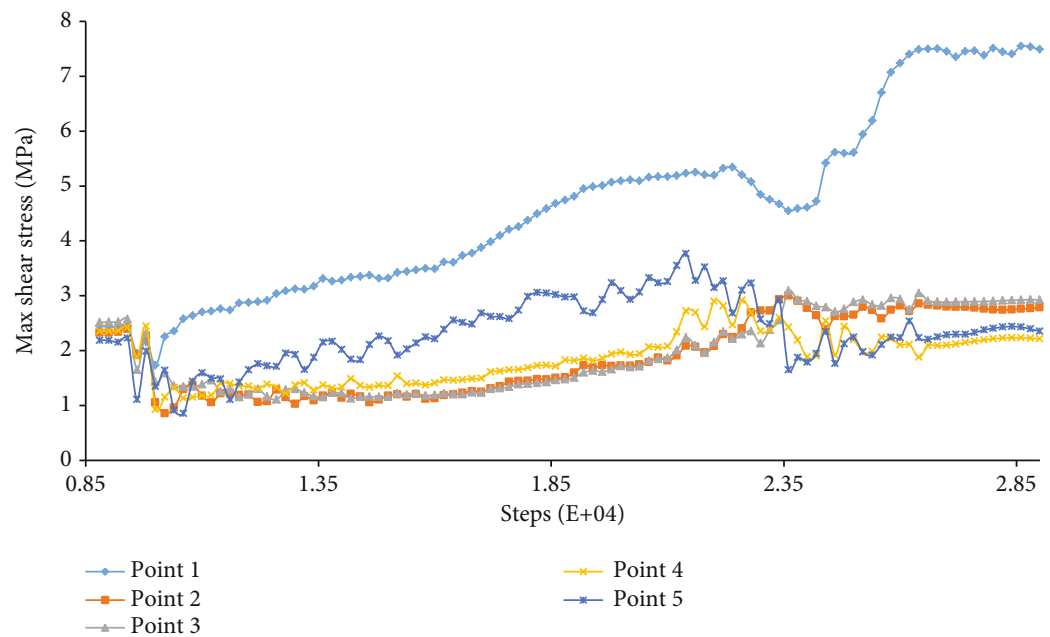

(a) $70 \mathrm{~m}$ line

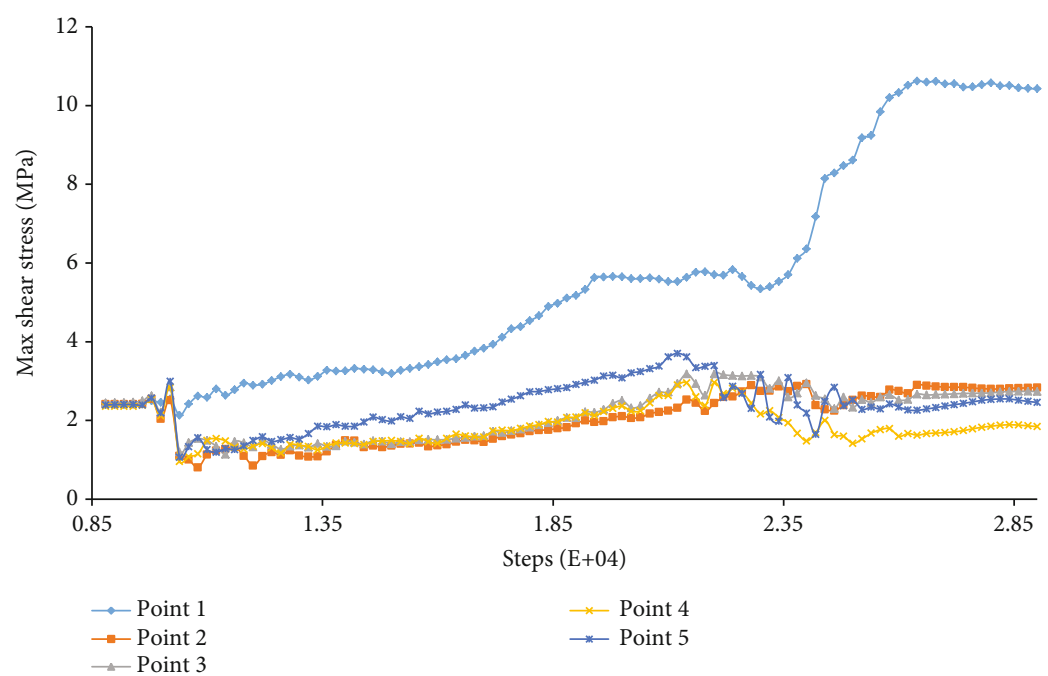

(b) $80 \mathrm{~m}$ line

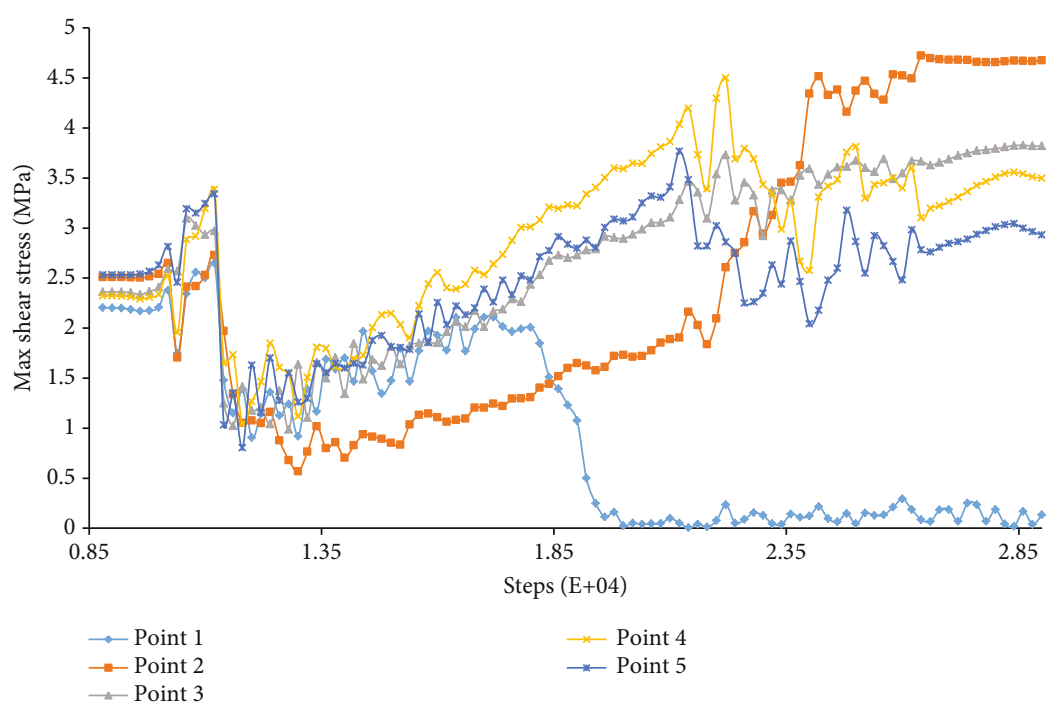

(c) $90 \mathrm{~m}$ line

Figure 11: Continued. 


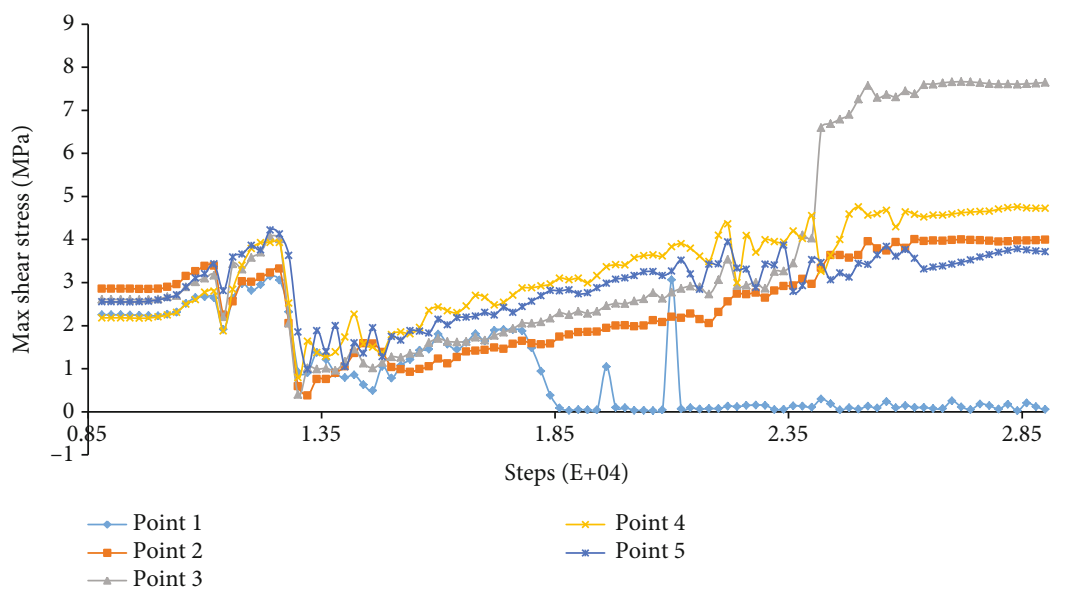

(d) $100 \mathrm{~m}$ line

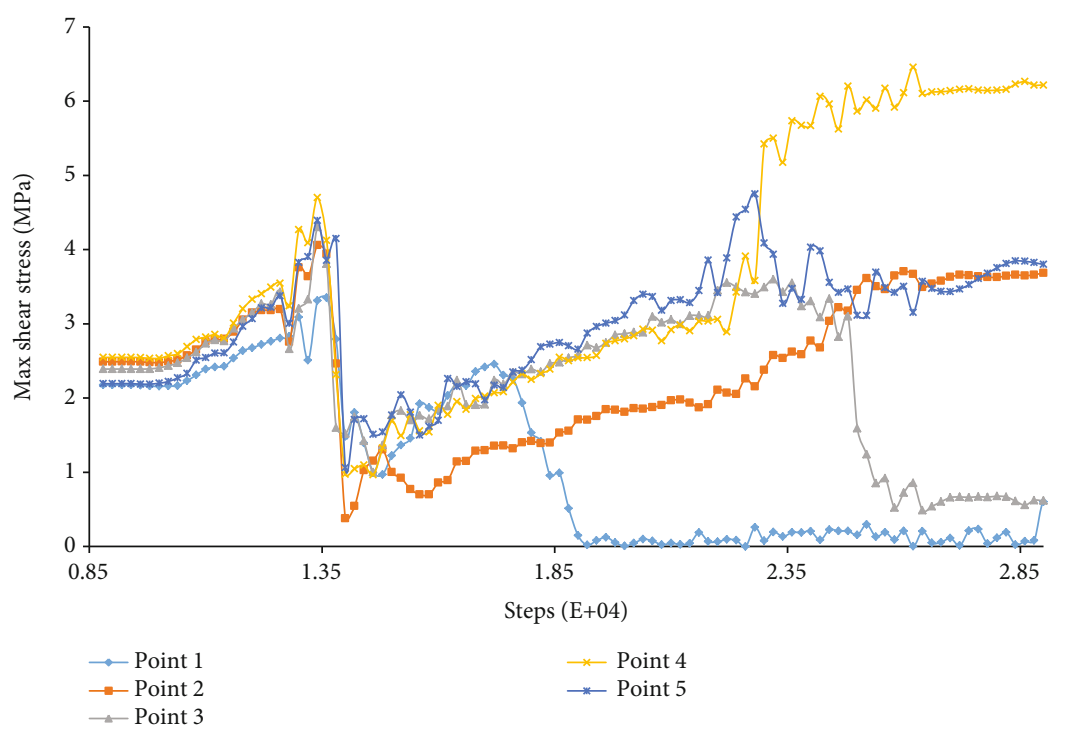

(e) $110 \mathrm{~m}$ line

Figure 11: $L=200 \mathrm{~m}, H=2.5 \mathrm{M}$ shear stress trends.

maximum shear stress except the stress at the boundary point. It rises to the stress fluctuation zone to produce a fluctuating drop and then quickly drops to a less stressful position. It is shown that the rock mass in point 5 occurs with sliding instability and the instability strength is large.

At the $80 \mathrm{~m}$ line, as shown in Figure 11(b), point 1 shear stress rises rapidly in the stress fluctuation area and remains relatively stable at the higher stress position. Indicating that the rock mass at this position has a greater tendency to slip, there may be a fall instability. The trend of shear stress change is relatively stable, and the possibility of falling instability is small. Measuring points 4 and 5 shear stress steady decline after rising to the stress fluctuation area. Indicating that the measured points 4,5 rock slippage but slippage intensity is weak.

At the $90 \mathrm{~m}$ line, as shown in Figure 11(c), point 1 shear stress decreases to about zero after a period of time to fluctuate update. This is the rock occur to sliding instability and the rock mass at the measuring point is disengaged from the contact rock, so the shear stress is reduced to zero. The shear stress of measuring point 2 rises steadily and rises to the stress large position in the stress fluctuation area, which indicates that point 2 has a strong tendency to slip and there may be a falling instability to form a friction surface. Point 3 shear stress steady rise stress fluctuates little but stress is large, indicating that the location of the measured point 3 rock has a strong trend of falling instability. Measuring points 4 and 5 shear stress rise to the stress fluctuation area were shock drop. After the shear stress is still in a larger position, indicating that the measured points 4 and 5 at the rock block occurred a in a more dramatic fall instability.

At the $100 \mathrm{~m}$ line, as shown in Figure 11(d), the shear stress of point 1 rises steadily and then decreases to about 0 . It is shown that the boundary rock mass at point 1 occurred to sliding instability. The trend of points 2,4 , and 5 shear stress change is relatively stable in the stress fluctuation area. But the impact is not large, stress in a higher position, resulting in falling instability being larger. The shear stress of measuring point 2 rises steadily in the initial stage, 


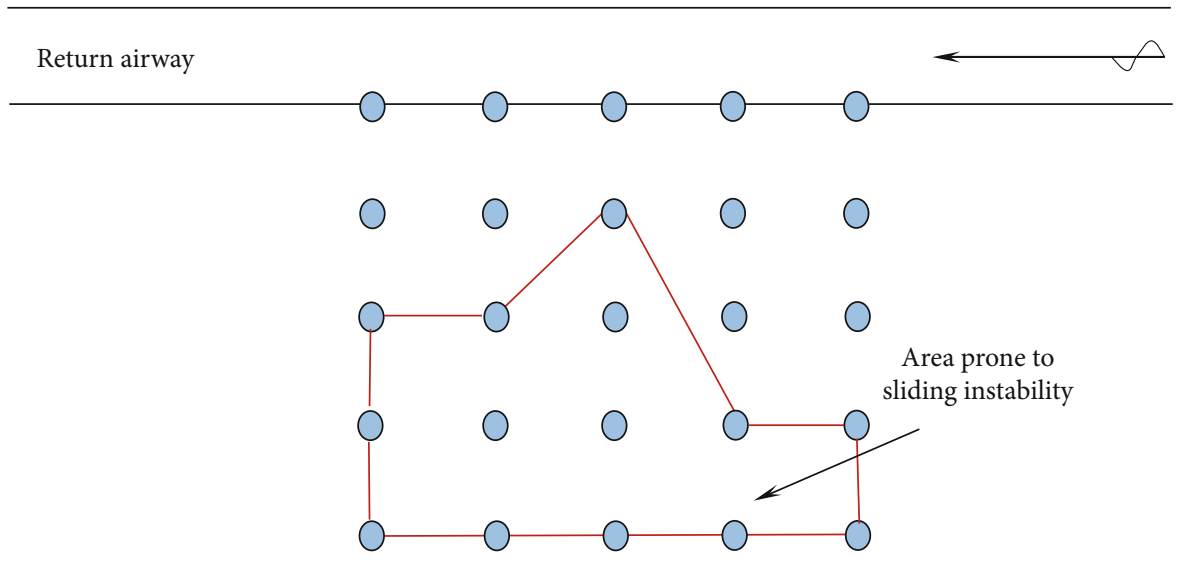

Figure $12: L=200 \mathrm{~m}, H=2.5 \mathrm{M}$ of the face prone to instability area.

and the stress increases rapidly in the stress fluctuation zone to reach the relatively high stress position. As the shear stress increases suddenly, the shear stress of the rock mass increases instantaneously, which may exceed the friction between the rock mass, which has the possibility of large falling instability and high instability strength.

At the $110 \mathrm{~m}$ line, as shown in Figure 11(e), points 1 and 3 shear stress suddenly drop to 0 after rising a period of time. The shear stress of point 3 rock mass later indicates that the rock mass at points 1 and 3 occurred to sliding instability. Point 2 shear stress steadily rises, resulting in falling instability increasing. The shear stress of point 4 is increased in the stress fluctuation area, and it rises steadily to the high level for a period of time. It shows that the measured point 4 rock block has a strong tendency to slip and be instable. The shear stress of point 5 is steadily increasing and then rises and falls rapidly in the stress fluctuation area. The shear stress has been relatively high at each point, which indicates that the rock mass at point 5 was fluctuating and unstable in the stress fluctuation area and the strength is greater.

From the above analysis, we can see that the area is easy to produce sliding instability and form a friction surface, as shown in Figure 12.

In summary, from Figures 5 and 7-9, comparative study shows, with the increase of the roof thickness of the working face, the possibility of forming the friction surface in the goaf is increased. When the thickness of the roof is thickened, it is possible to form a region with a wider range of sliding instability, resulting in a more severe degree of sliding instability.

\section{Conclusions}

(1) Frictional thermal effect is the root cause of roof collapse and ignition gas. For roof fracture rock blocks in engineering site, when sliding friction occurs due to sliding instability, the friction surface is usually narrow in space and a large amount of mechanical energy is converted into heat energy and accumulated and heated at the friction surface. The hightemperature friction surface is the main ignition source of igniting gas
(2) It can be used to judge overlying stata occurring with sliding instability by the change trend of the internal shear stress. When the shear stress of a point decreases sharply, the overlying strata may occur with sliding instability in this position

(3) In the tunnel boundary to bear the maximum shear stress, where the most prone to fall instability and the formation of friction surface

(4) After increasing the length of the working face, it has little effect on the area of the overburden hard rock strata which is prone to sliding instability and form the friction surface. When the thickness of the roof is increased, the sliding friction becomes more intense and the area where the friction surface is liable to be increased increases

\section{Outlook}

This paper verifies the possibility of gas ignition by the friction effects of rock through laboratory experiments. This conclusion has general applicability for specific types of rocks. Through numerical simulation, the areas where sliding friction may occur under different rock strata conditions during coal mining are discussed. In the future, it is necessary to consider the actual engineering conditions of the coal mine, and $\mathrm{R} \& \mathrm{D}$ advanced testing methods and testing techniques, in order to further clarify the possible scope of frictional instability, so as to make the control of such accidents more targeted.

\section{Data Availability}

All data are obtained through experiments and numerical simulation without reference or borrowing from others. The data used to support the findings of this study are available from the corresponding author upon request.

\section{Conflicts of Interest}

The authors declare no conflicts of interest. 


\section{Acknowledgments}

This study was sponsored by the Shandong Provincial Key R\&D Plan of China (Grant No. 2019SDZY034-1), the Engineering Laboratory of Deep Mine Rockburst Disaster Assessment Open Project (LMYK2020007), the National Natural Science Foundation of China (Grant Nos. 51504145, 51804182), and the Shandong Provincial Institute of Science and Technology Plan (Grant No. J17KB041). The authors are grateful for their support.

\section{References}

[1] C. Weimin, X. Song, and L. Weitao, Mining ventilation and safety, Coal Industry Press, Beijing, 2009.

[2] Office of the Security Council of the State Council, "The "6.3" major gas explosion accident investigation report of Yan Shitai coal mine in Nantong Mining Limited liability company of Chongqing energy investment group," 2015, http://www .chinasafety.gov.cn/newpage/Contents/.

[3] R. Hauke and F. Guo, "Circuit ignition characteristic of intrinsic safety and high frequency-higher than industrial alternating current frequency," Electric Explosion Protection, vol. 1, pp. 30-34, 2005.

[4] M. L. Skow, A. G. Kim, and M. Deul, "Creating a safer environment in U.S. coal mines: the Bureau of Mines methane control program," Dept. of the Interior Bureau of Mines, Washington D.C.: U.S, 1980.

[5] K. Ghana, "British gas explosion and safety management measures," International Mining and Minerals, vol. 7, pp. 197-204, 1999.

[6] Hayatsuki Uchida, "Research on high speed impact friction spark methane inflammability," World Coal Technology, vol. 6, pp. 39-42, 1985.

[7] V. I. Golinko, A. V. Yavorskiy, Y. Lebedev, and Y. A. Yavorskaya, "Estimation of frictional sparking effect on firedamp inflammation during fragmentation of as-saturated rock massif," Naukovyi Visnyk Natsionalnoho Hirnychoho Universytetu, vol. 6, pp. 31-37, 2014.

[8] Q. D. Qu, J. L. Xu, W. D. Ma, S. H. Zhang, and K. Jiang, "Experimental study on gas explosion detonated by the rock friction sparks," Journal of China Coal Society, vol. 31, no. 4, pp. 466-469, 2006.

[9] Q. Yujin, J. Wenzhong, and W. Xueyang, "Determination of ignition source of gob gas explosion (burning)," Safety in Coal Mine, vol. 36, no. 7, pp. 35-37, 2005.

[10] Q. D. Qu, J. L. Xu, W. D. Ma, S. H. Zhang, and K. Jiang, "Experimental study on gas explosion ignited by the rock friction," Safety in Coal Mine, vol. 33, no. 12, pp. 8-10, 2002.

[11] C. R. Ward, R. Cohen, D. Panich, A. Crouch, S. Schaller, and P. Dutta, "Assessment of methane ignition potential by frictional processes from Australian coal mine rocks," Mining science \& technology, vol. 13, no. 2, pp. 183-206, 1991.

[12] V. V. Kalinchak and Y. M. Mikhel', "Time to ignite a gas with a friction spark," Journal of Engineering Physics, vol. 51, no. 1, pp. 845-847, 1986.

[13] J. C. Wang, J. X. Wang, J. Shen, and P. Guo, "Experimental research on gas hazard incident caused by roof collapse," Journal of Mining \& Safety Engineering, vol. 24, no. 1, pp. 8-11, 2007.
[14] Y. F. Bulgakov, "Experimental investigation of explosionsuppression properties of gob rocks under laboratory and mine conditions," Procedia Earth and Planetary Science, vol. 1, no. 1, pp. 199-202, 2009.

[15] G. Qin, Z. Wen, C. Wang, Z. Zhang, and D. Meng, "Goaf gas ignition due to hard and thick rock stratum fracture friction effects: a case study," Geotechnical and Geological Engineering, vol. 37, no. 3, pp. 1569-1584, 2019.

[16] Q. Guangpeng, W. Chao, Z. Zhongteng, and P. Yunxin, "Primary study of goaf gas ignition mechanism by collapse of hard and thick sandstone roof stratum," Chinese Journal of Rock Mechanics and Engineering, vol. 38, Supplement 1, pp. 29252933, 2019.

[17] Z. Dangwei and Z. Baisheng, "Theoretical analysis of frictional firing (explosion) gas in roof of goaf," Coal mine safety, vol. 47, no. 1, pp. 141-144, 2016.

[18] P. Gou, "Theory analysis of gas hazard incident caused by roof caving," Journal of Mining \& Safety Engineering, vol. 23, no. 4, pp. 379-382, 2006. 